\title{
Evaluation and management of acquired ptosis
}

\author{
Stephanie E. Farber ${ }^{1}$, Mark A. Codner ${ }^{2}$ \\ 'Department of Plastic Surgery, University of Pittsburgh, PA 15261, USA. \\ ${ }^{2}$ Division of Plastic Surgery, Emory University, Atlanta, GA 30322, USA.
}

Correspondence to: Dr. Mark A. Codner, Mark Codner Plastic Surgery, 1800 Howell Mill Rd, Suite 140, Atlanta, GA 30318, USA. E-mail:macodner@gmail.com; mark@markcodnermd.com

How to cite this article: Farber SE, Codner MA. Evaluation and management of acquired ptosis. Plast Aesthet Res 2020;7:20. http://dx.doi.org/10.20517/2347-9264.2020.05

Received: 7 Jan 2020 First Decision: 20 Mar 2020 Revised: 24 Mar 2020 Accepted: 10 Apr 2020 Published: 23 Apr 2020

Science Editors: Allen M. Putterman, Chau Pham Copy Editor: Jing-Wen Zhang Production Editor: Jing Yu

\begin{abstract}
Periorbital rejuvenation is a common aesthetic goal sought by patients presenting to the plastic or oculoplastic surgeon. For this reason, it is critical that the surgeon understand the functional considerations, such as preexisting blepharoptosis, which will contribute to the ultimate aesthetic outcome. This article will review the anatomy of the normal and ptotic lid and will discuss the approach to diagnosing and characterizing the type and degree of lid ptosis. High-yield surgical techniques for ptosis correction will then be described, including the indications for and steps of each procedure. Finally, the diagnosis and management of common complications that follow ptosis surgery will be discussed. Our main objective is to arm the surgeon with the preoperative and operative planning tools to successfully manage comorbid ptosis and thereby improve blepharoplasty outcomes.
\end{abstract}

Keywords: Functional eyelid surgery, eyelid ptosis, acquired ptosis, blepharoplasty, blepharoptosis, periorbital rejuvenation

\section{INTRODUCTION}

The eyes are the focal point of the face. For this reason, it is common for patients to present to plastic surgeons seeking an aesthetic, youthful periorbital appearance. Upper and lower lid blepharoplasty are key operations intended to rejuvenate the periorbital region. However, given the many functional considerations involved in eyelid and periorbital surgery, a thorough preoperative evaluation may reveal other functional issues that must be addressed at the time of aesthetic eyelid surgery.

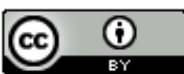

(C) The Author(s) 2020. Open Access This article is licensed under a Creative Commons Attribution 4.0 International License (https://creativecommons.org/licenses/by/4.0/), which permits unrestricted use, sharing, adaptation, distribution and reproduction in any medium or format, for any purpose, even commercially, as long as you give appropriate credit to the original author(s) and the source, provide a link to the Creative Commons license, and indicate if changes were made.

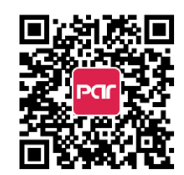




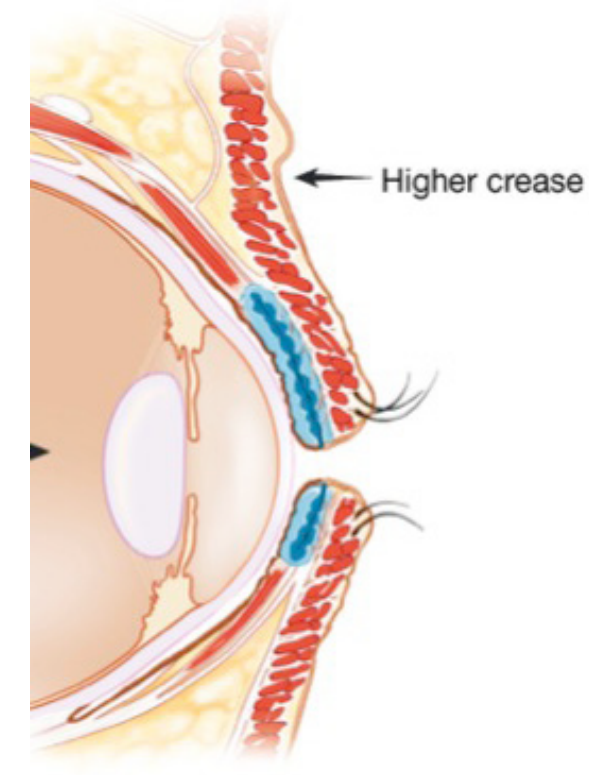

Figure 1. Attachments of the levator aponeurosis to the lid crease, which elevates with ptosis and Mueller's muscle originating from the undersurface of the levator inserting into the superior tarsal plate

In addition to xerophthalmia, lower eyelid malposition, and other eyelid problems that cause functional disability and may be addressed surgically, upper lid ptosis, or abnormal drooping of the upper lid, is a common comorbidity encountered in patients presenting for periorbital rejuvenation. This complex anatomic problem should be treated concurrently to achieve optimal periorbital aesthetics and function.

This review will provide the plastic surgeon with a structured approach to the evaluation and treatment of lid ptosis. Following a basic summary of normal and aged upper lid anatomy, we will outline the preoperative workup of a patient presenting for upper eyelid rejuvenation, including techniques for identifying the presence and etiology of lid ptosis. We will then review the indications for particular surgical procedures. These operative techniques will be outlined in detail, followed by a description of the evaluation and management of common complications resulting from surgical correction of lid ptosis.

\section{ANATOMY}

\section{Normal}

The upper eyelid consists of an anterior and posterior lamella separated by the orbital septum. The anterior lamella includes the thin upper lid skin and the orbicularis oculi muscle. The posterior lamella contains the tarsal plate, lid retractors, and the conjunctiva [Figure 1] $]^{[1]}$.

The upper lid retractors include the levator palpebrae superioris and Müller's muscle. These are the structures responsible for elevating the lid and are most relevant to the development of ptosis. The levator muscle is a striated muscle innervated by cranial nerve III (oculomotor nerve) and extends from the lesser wing of the sphenoid to the level of Whitnall's ligament. Whitnall's ligament is a fascial sheath of the levator muscle that serves as a check ligament and upper lid support structure. At this level, the levator muscle becomes the levator aponeurosis and attaches to the anterosuperior tarsus, orbital septum, and upper lid skin, creating the upper lid crease [Figure 2]. Müller's muscle, innervated by the sympathetic nervous system, originates from the undersurface of the levator aponeurosis and attaches to the superior tarsus [Figure 3] ${ }^{[1]}$. 


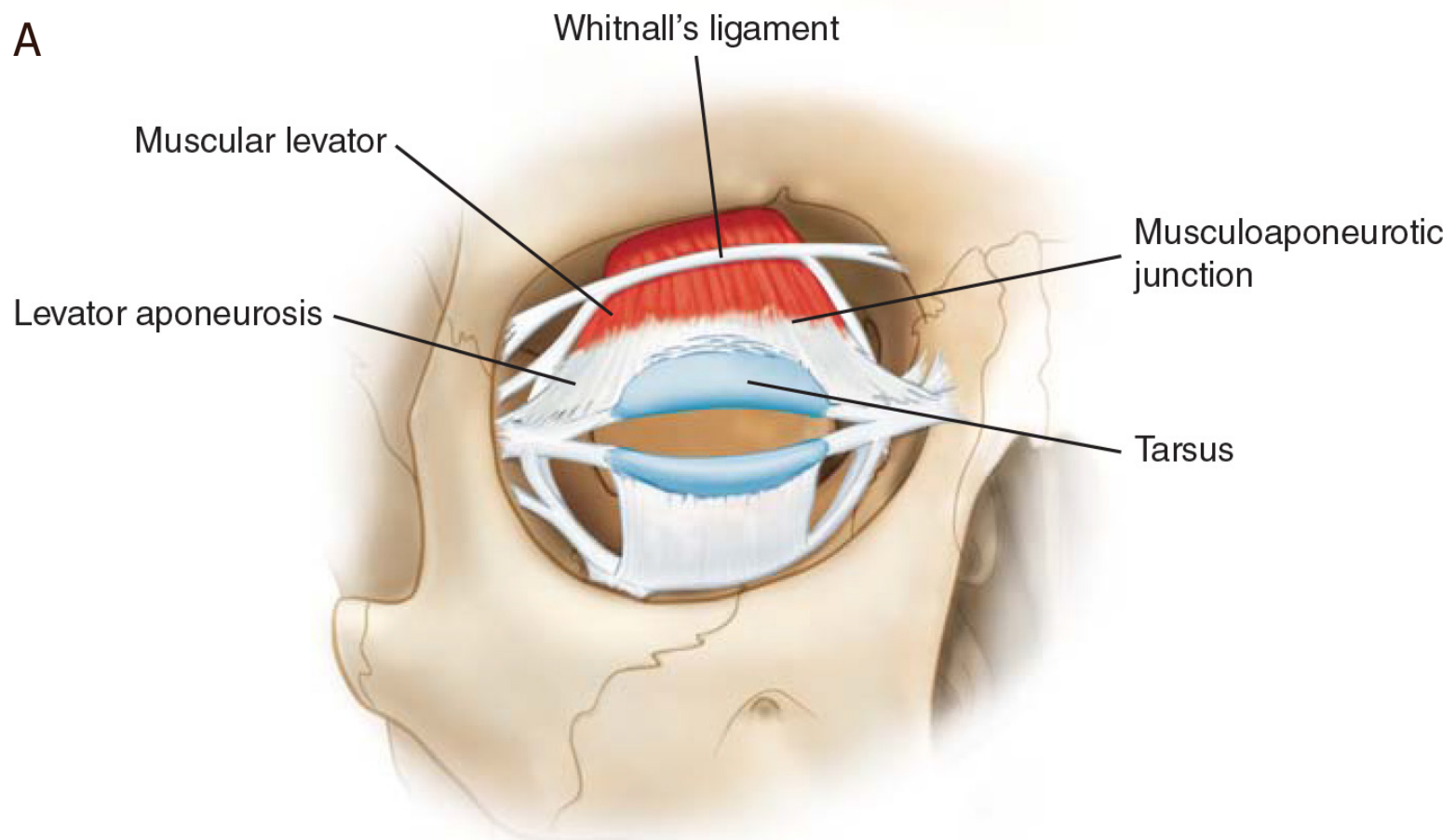

B

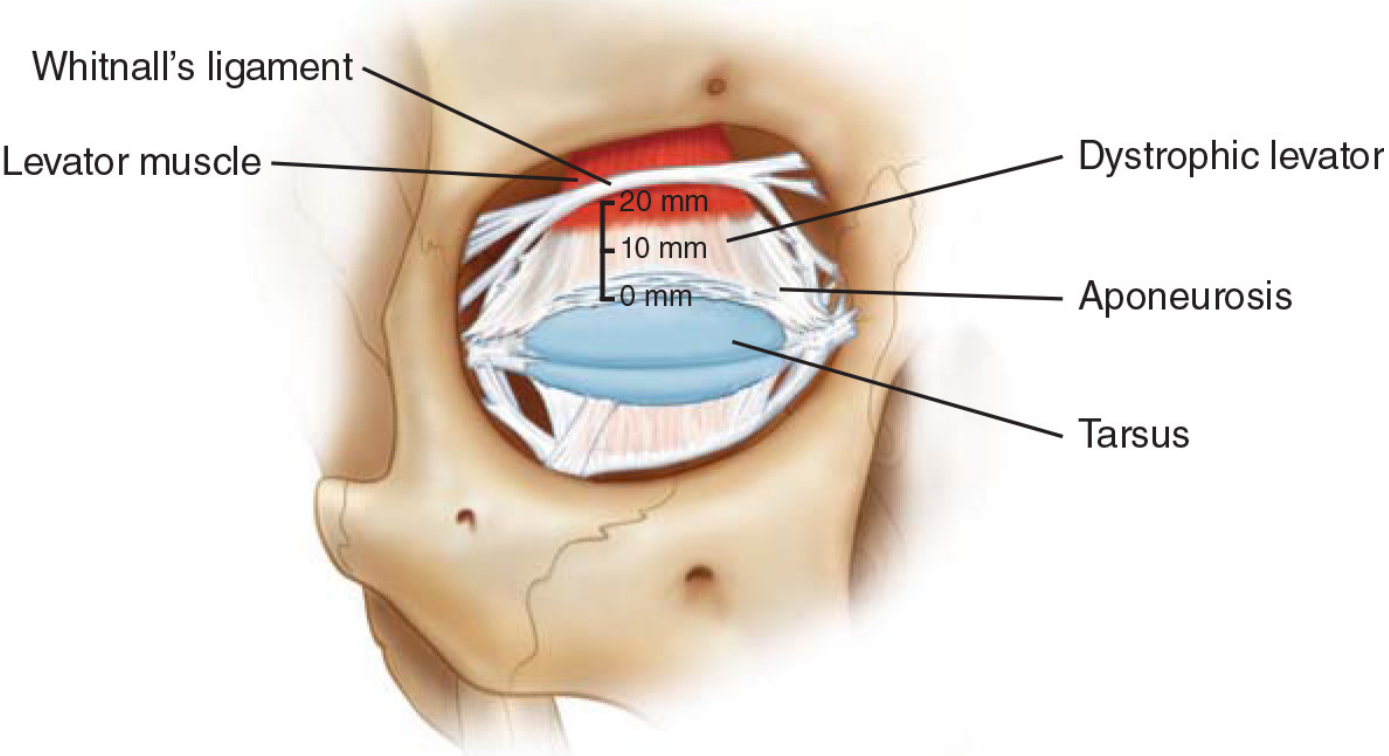

Figure 2. A: the relationship of the levator muscle to the musculoaponeurotic junction and tarsal plate; B: the distance from the superior border of the tarsal plate and the levator muscle increases with a dystrophic muscle and aponeurosis

\section{Ideal eyelid}

The aesthetic upper lid consists of a well-defined supratarsal crease with a visible pretarsal space that is not covered by overhanging upper lid skin [Figure 4]. The upper lid sulcus should be a visible concave area between the lid crease and the superior orbital rim without prominent hollows or bulges. The ideal upper lid margin should lie just below the upper corneal limbus ${ }^{[2]}$. 


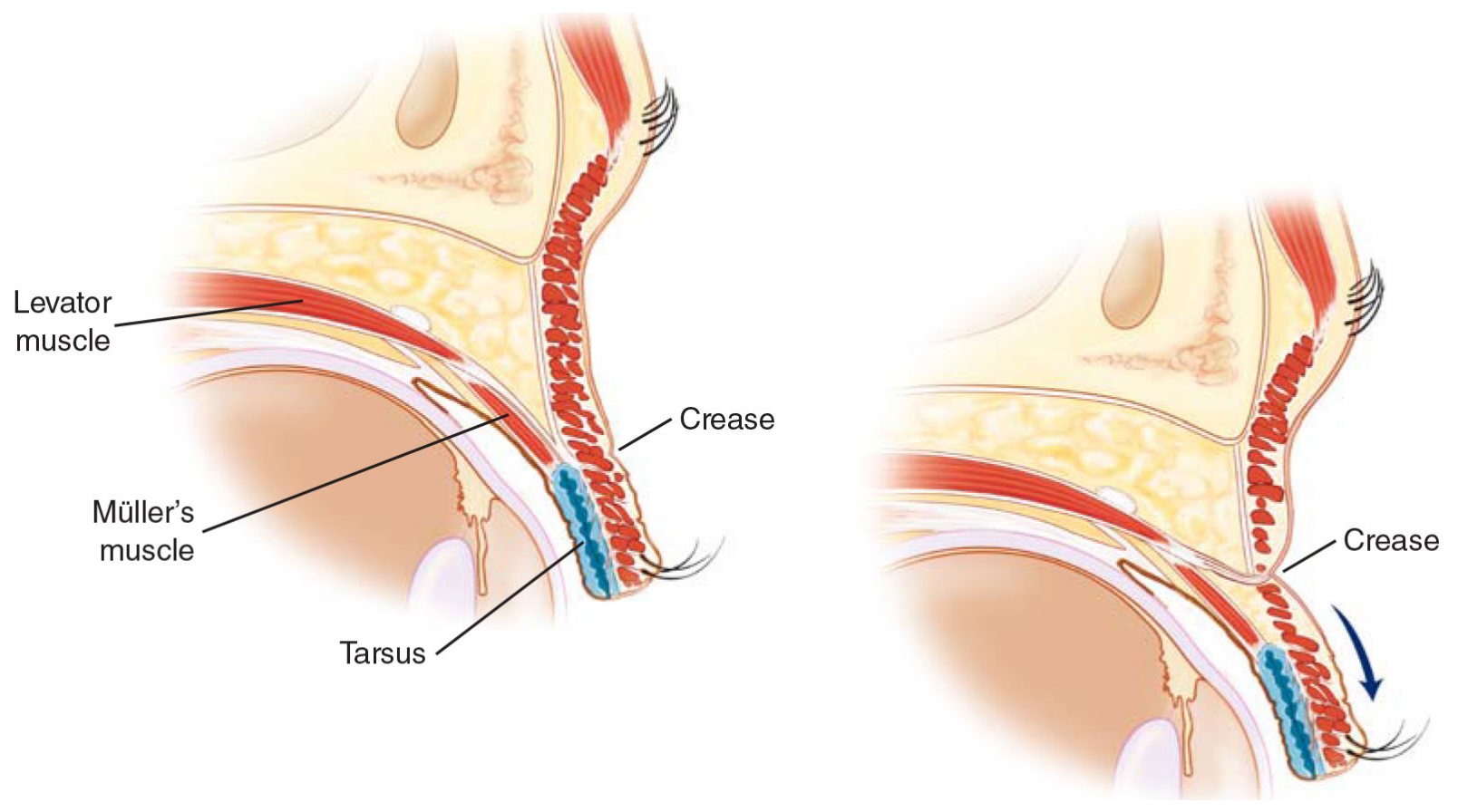

Figure 3. As the lid becomes ptotic, the levator pulls the crease superiorly

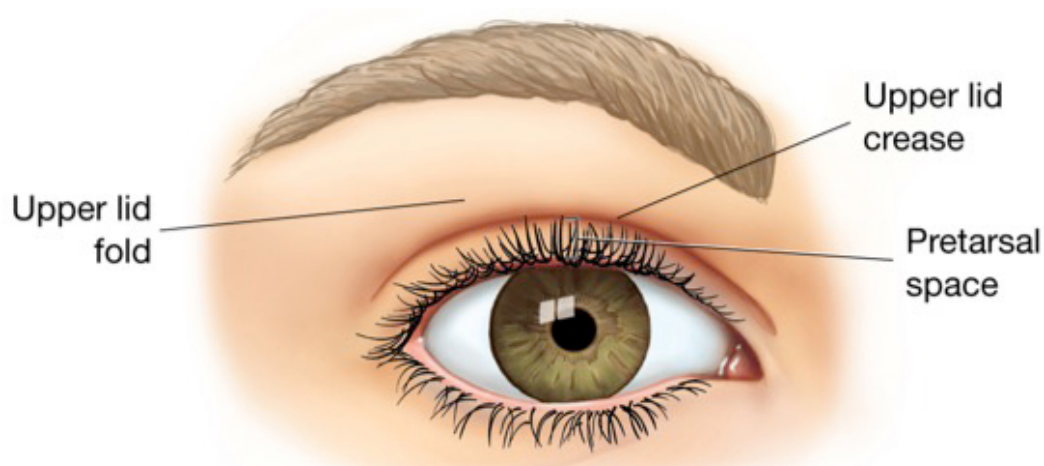

Figure 4. The relationship of the lid fold which folds over the crease. The terms should not be used interchangeably. The pretarsal space and lid margin are in good position with a symmetrical arch

\section{Photic eyelid}

The ptotic lid is characterized by a decreased margin to reflex distance 1 and a reduced palpebral fissure [Figure 5]. These measures will be reviewed in more detail in the "Patient Evaluation" section. Myogenic, neurogenic, mechanical, and involutional ptosis all have distinct anatomic etiologies that may lead to these examination findings. Myogenic ptosis occurs secondary to myasthenia gravis, neurologic ptosis secondary to dysfunction of the third cranial nerve (such as in Horner's syndrome), and mechanical ptosis secondary to trauma, hard contacts, or prior blepharoplasty. The focus of this article is on involutional ptosis, which is caused by dehiscence of the levator aponeurosis from the tarsal plate. As the lid falls, the levator attachments to the skin remain intact, causing an elevation of the upper lid crease [Figure 6] ${ }^{[3]}$.

\section{DIFFERENTIAL DIAGNOSIS}

First, it must be determined whether lid ptosis is congenital or acquired. A diagnosis of congenital ptosis requires alternative techniques for surgical correction, since the levator is characteristically fibrotic. The key physical examination finding in congenital ptosis is lid lag on downgaze [Figure 7$]^{[4]}$. 


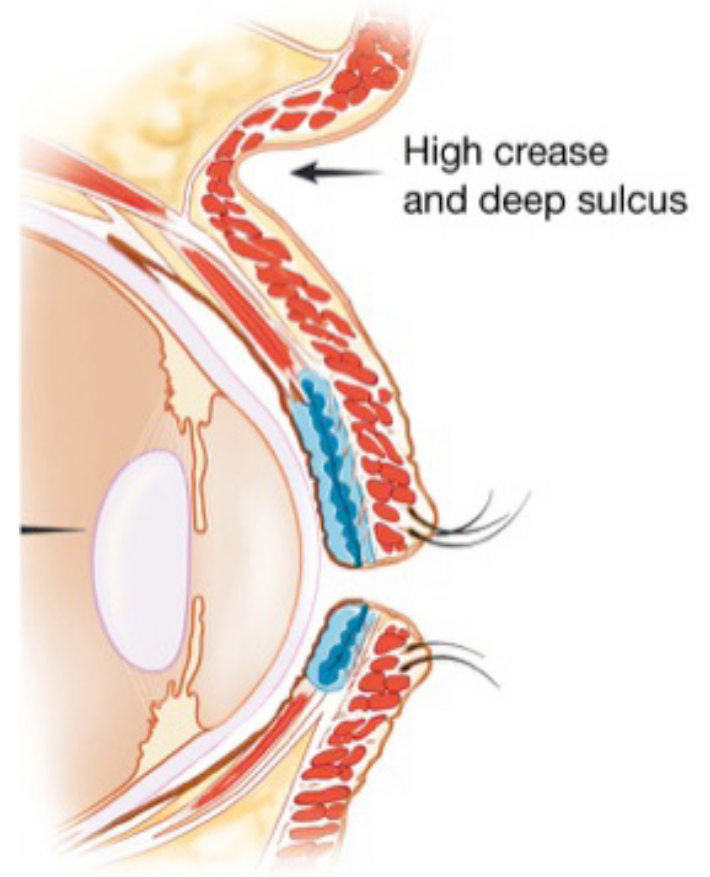

Figure 5. Close-up view of the deris of the lid crease moving higher as the levator withdraws and the lid drops

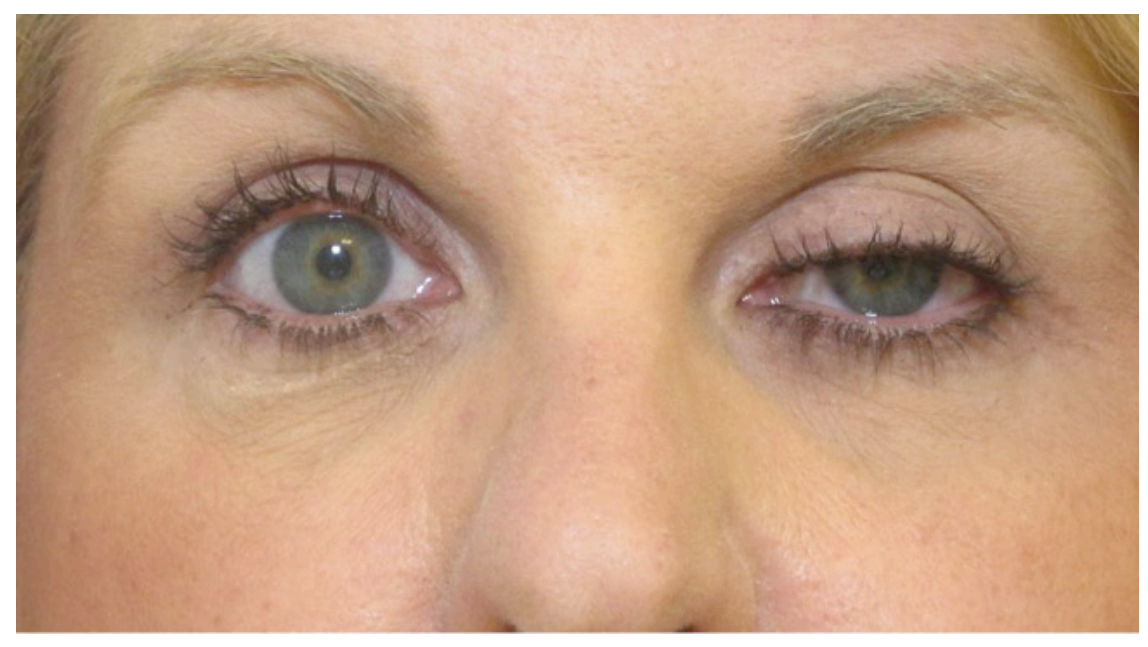

Figure 6. Patient 1 year after upper blepharoplasty and early postoperative left hematoma managed conservatively

Acquired ptosis can be due to forces extrinsic or intrinsic to the upper lid [Figure 8]. Extrinsic lid ptosis is secondary to factors outside of the upper lid, such as mechanical forces on the upper lid (brow ptosis, dermatochalasis, or tumor), contralateral lid retraction (most commonly secondary to thyroid disease), enophthalmos, orbicularis spasm, or facial nerve abnormalities ${ }^{[4]}$.

Intrinsic lid ptosis can be aponeurotic, myogenic, or neurogenic. The management of neurogenic and myogenic lid ptosis requires a specialized neurological evaluation. Aponeurotic ptosis will be the focus of this article and can be secondary to attenuation of the aponeurosis, trauma, eyelid swelling, or ocular surgery ${ }^{[4]}$. One form of trauma after which patients may develop lid ptosis is following cataract surgery due to retraction injury and stretching of the levator muscle. 

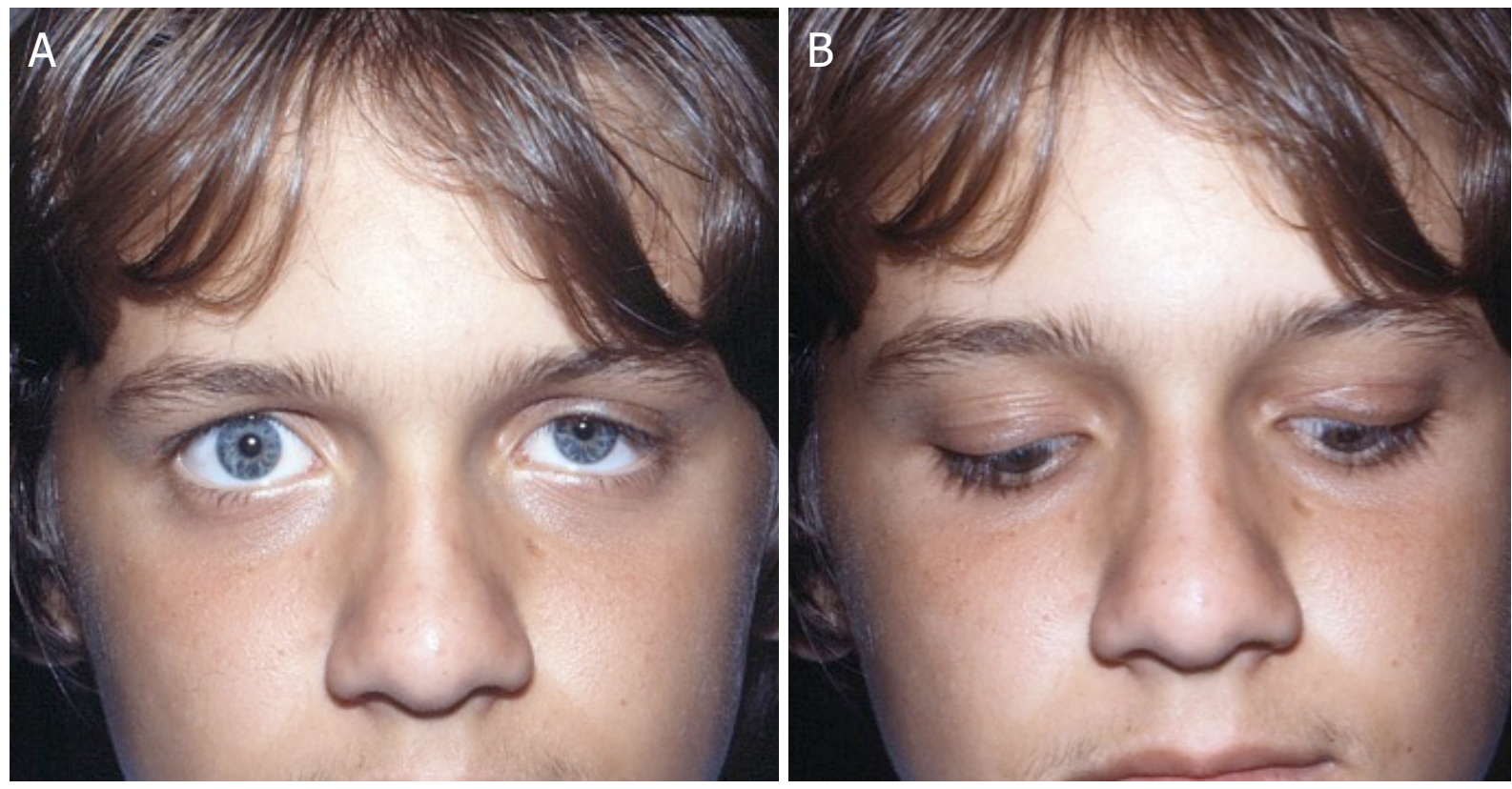

Figure 7. A: congenital ptosis in a child with left ptosis; B: the pathognomonic sign of left lagophthalmos in downgaze to restriction of the lid from fibrosis of the levator and Mueller's muscle
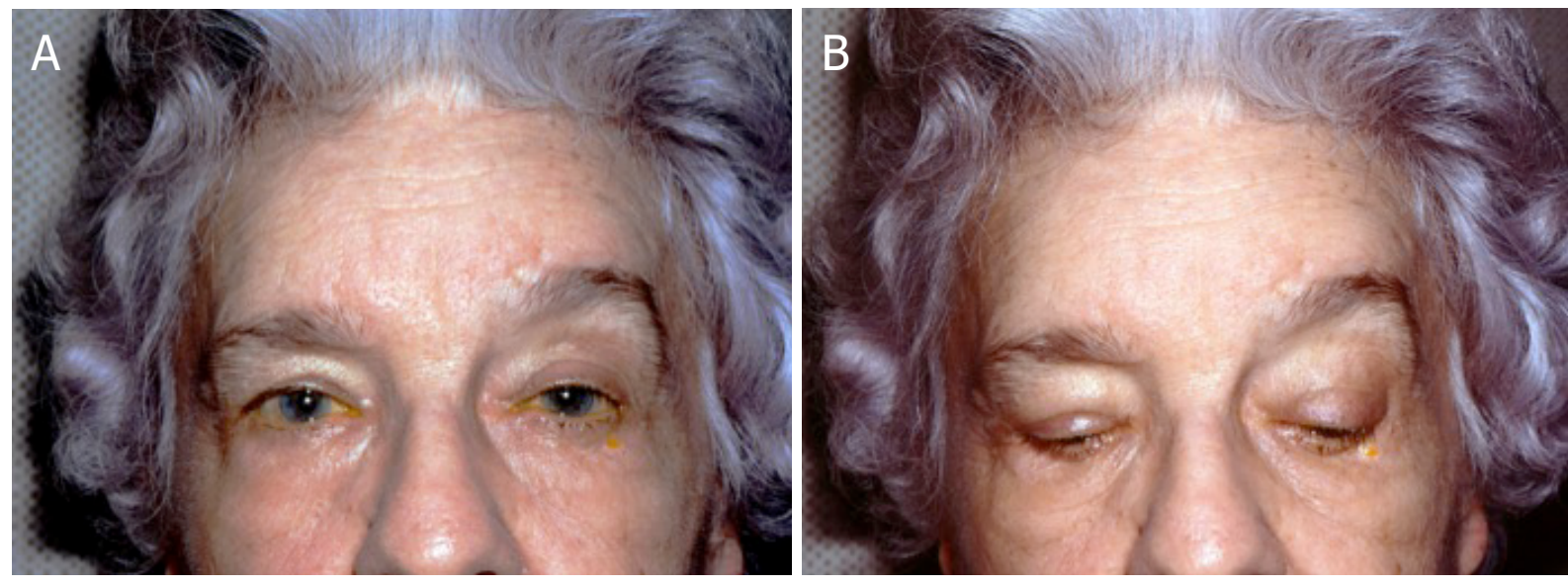

Figure 8. A: an elderly woman with bilateral ptosis worse on the left side from dehiscence of the levator aponeurosis; B: on downgaze, there is no restriction or lagophthalmos

\section{PATIENT EVALUATION}

\section{History}

As with any preoperative patient evaluation, the assessment must begin with a thorough medical history. In the case of an adult patient with new onset ptosis presenting for eyelid surgery, special attention must be paid to risk factors other than aging, including thyroid disease, diabetes, bleeding diatheses, periorbital surgery or trauma, other ocular conditions, and an orbital or brain tumor, which must be excluded by MRI or CT scan. These patients should be cleared for ptosis surgery by a neuro-ophthalmologist [Figure 9]. Adult patients who have acute acquired unilateral ptosis without a history of trauma, recent cataract or vision surgery when a speculum was used, or long-standing history of unilateral contact use should also be ruled out for development of an intraorbital or intracranial tumor. 

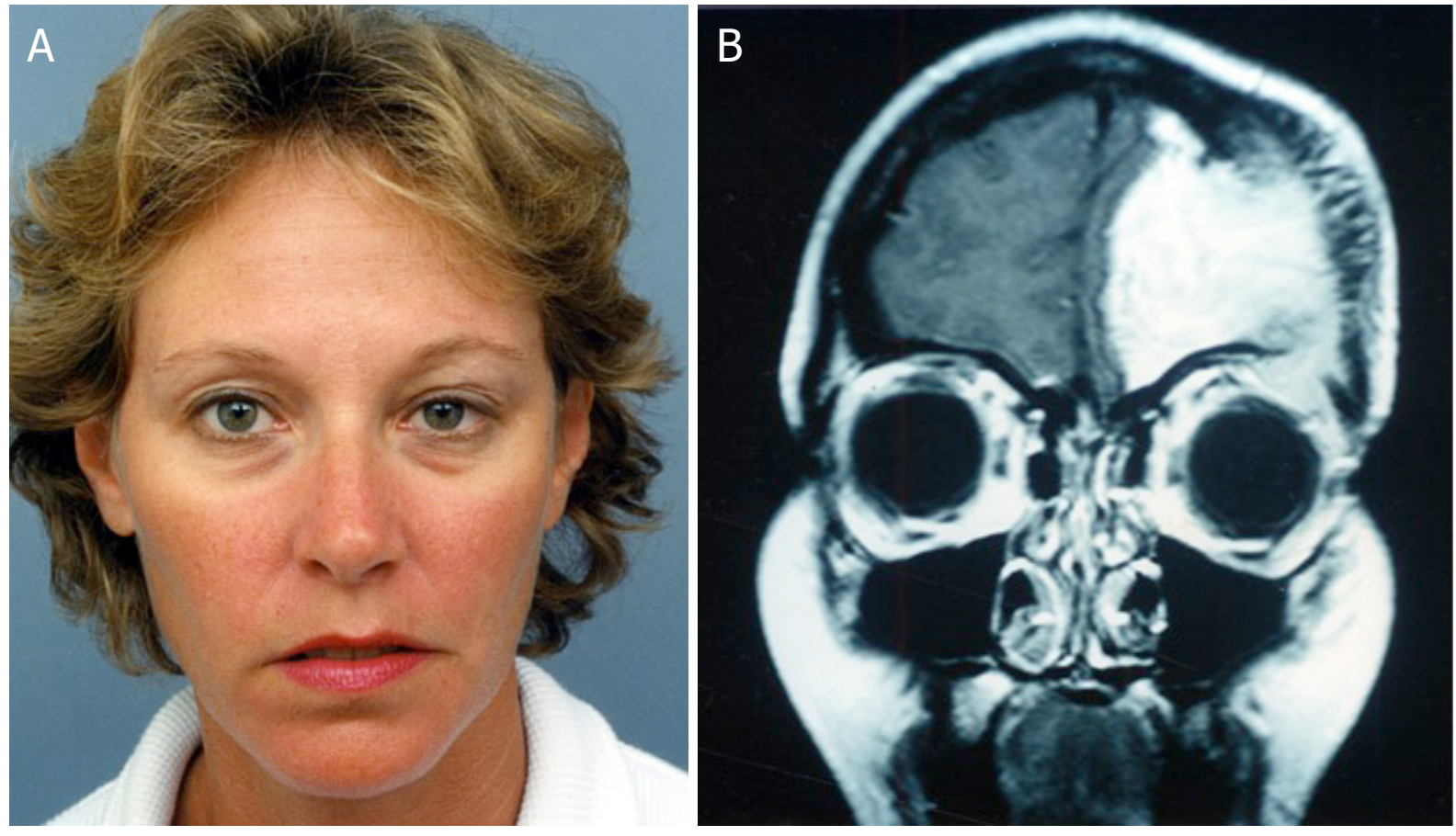

Figure 9. A: an otherwise healthy patient presents with newly acquired ptosis of the left eye with no significant history of a possible cause; B: MRI reveals a large left frontal meningioma eroding through the sphenoid wing causing ptosis and orbital dystopia

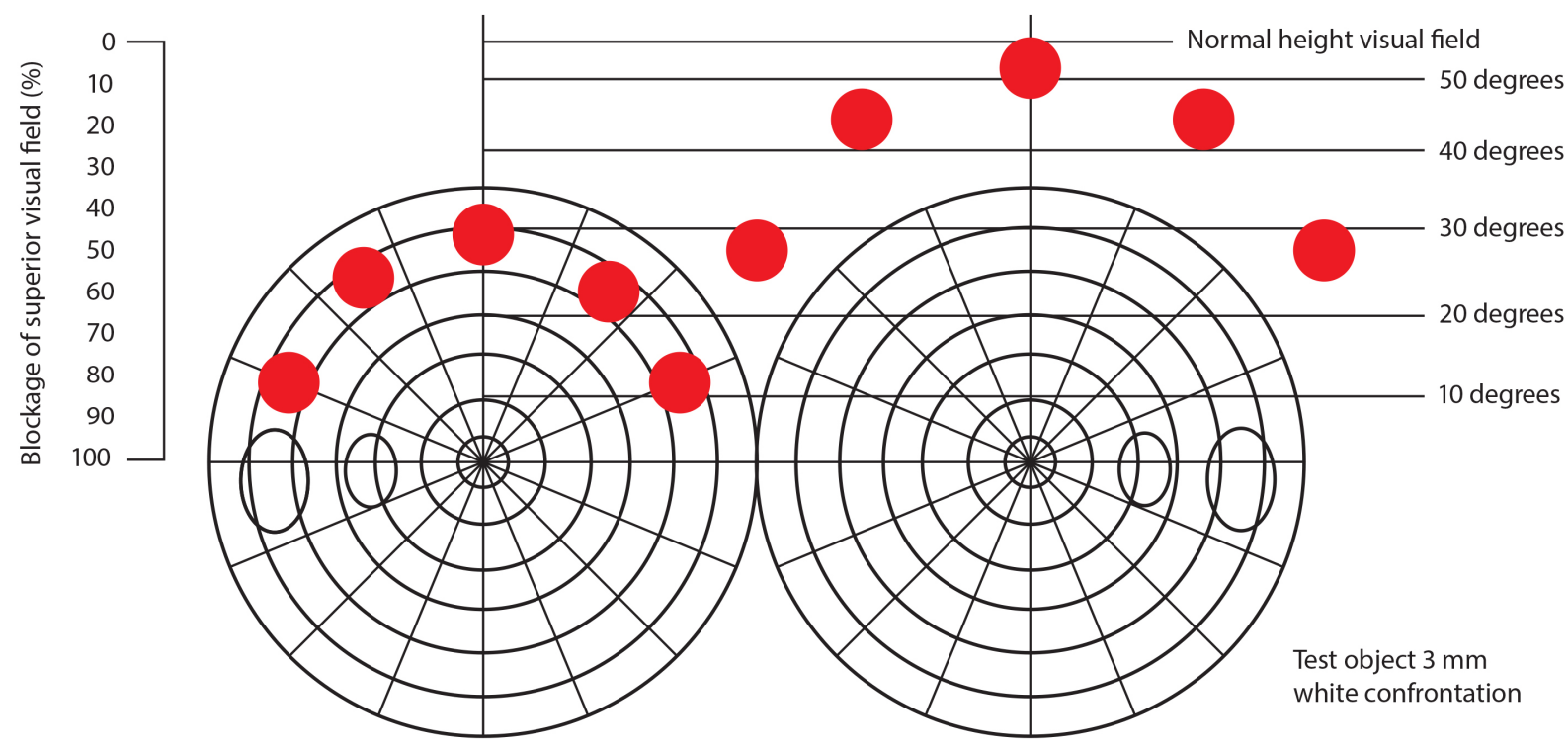

Figure 10. Example of a visual field test performed in the office with a Q-tip not a visual field machine, documenting the loss of $50 \%$ of the right superior visual field by confrontation test

Patients with acquired ptosis often complain of a progressive decrease in the size of their eyes, a tired appearance, and even visual field loss [Figure 10]. Risk factors for this finding include advanced age, contact lens use, cataract surgery, or history of lid edema such as blepharochalasis and floppy upper lid syndrome [Figure 11] $]^{[3]}$. Another medical disease that often presents as ptosis is myasthenia gravis. Specific questions should be asked, including if the patient has worsening of the ptosis at night and if there are other signs such as muscle weakness or difficulty breathing or swallowing. Physical examination will reveal 

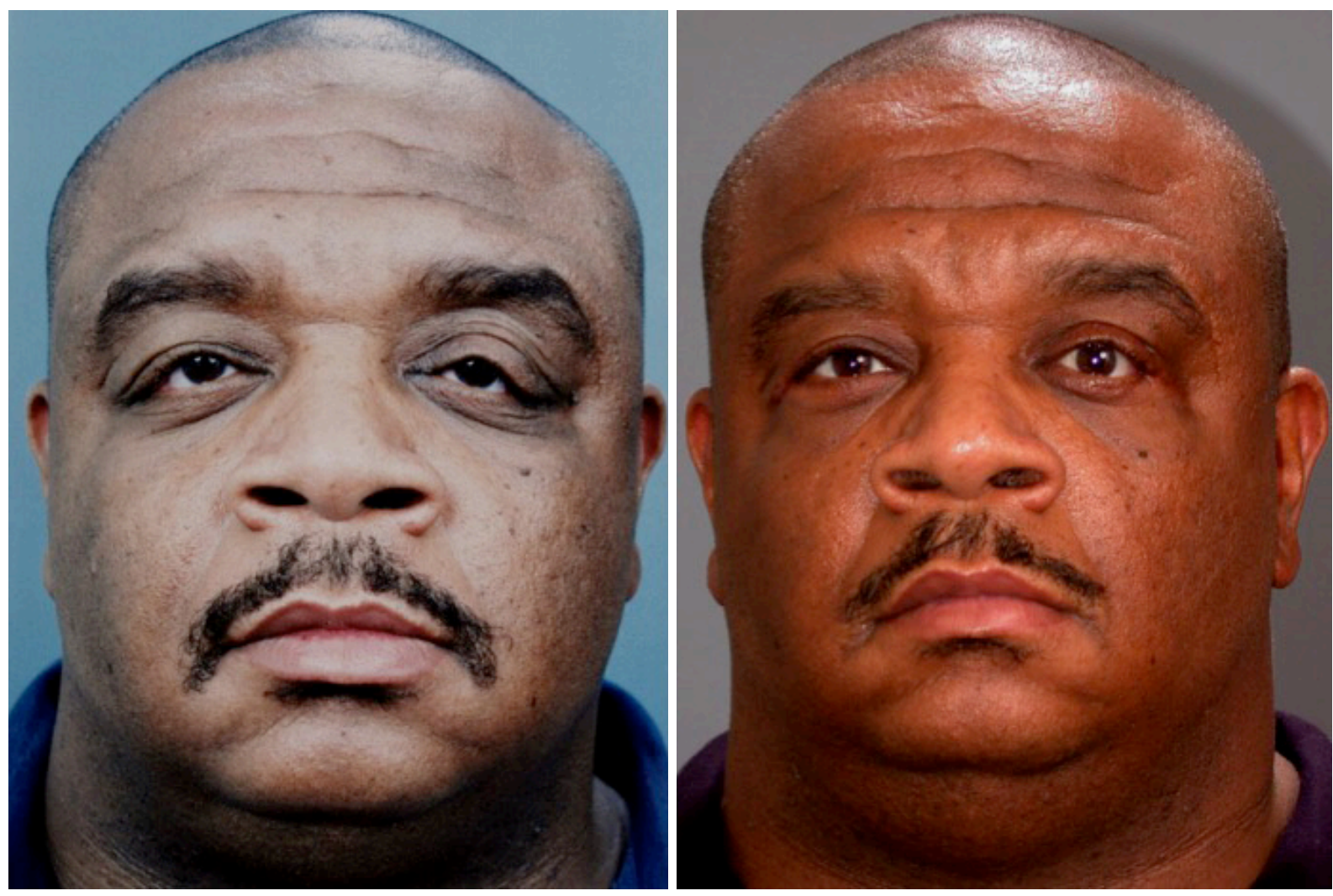

Figure 11. Large male with the hallmark appearance of floppy upper lid syndrome and ptosis

eyelid fatigability when the patient is instructed to close his or her eyes tightly, fatiguing the orbicularis and inhibiting the levator, and to open them rapidly. A positive test is defined by immediate upward movement of the lid secondary to the levator muscle, followed by downward drift. An adult with new onset signs and symptoms, including the ones just mentioned, should have a neuro-ophthalmologic evaluation including a Tensilon test.

Another important consideration is the presence of xerophthalmia, or dry eye syndrome. This syndrome is characterized by a disruption in the tear film either due to decreased production or increased evaporation. Symptoms such as burning, itching, foreign body sensation or other types of eye discomfort should be elucidated. Risk factors for dry eye syndrome include laser eye surgery, smoking, and certain medications. These risk factors should be mitigated prior to surgery and eye lubricating drops and ointments may also be used as adjuncts ${ }^{[3]}$.

Importantly, ptosis can be a key presenting sign in patients with the onset of neurological conditions. Therefore, in an adult presenting with ptosis, the absence of levator dehiscence, and the presence of other red flag symptoms such as diplopia, abnormal pupillary reflexes and difficulty with speech or swallowing, neurological evaluation is critical to rule out other potentially life-threatening conditions ${ }^{[1]}$.

\section{Physical examination}

Any ocular and periorbital examination should begin with an assessment of the globe, including visual acuity, extraocular movements, and pupillary response. Additionally, Bell's phenomenon should be documented to ensure that the patient's cornea will be protected postoperatively [Figure 12 ${ }^{[5]}$. 


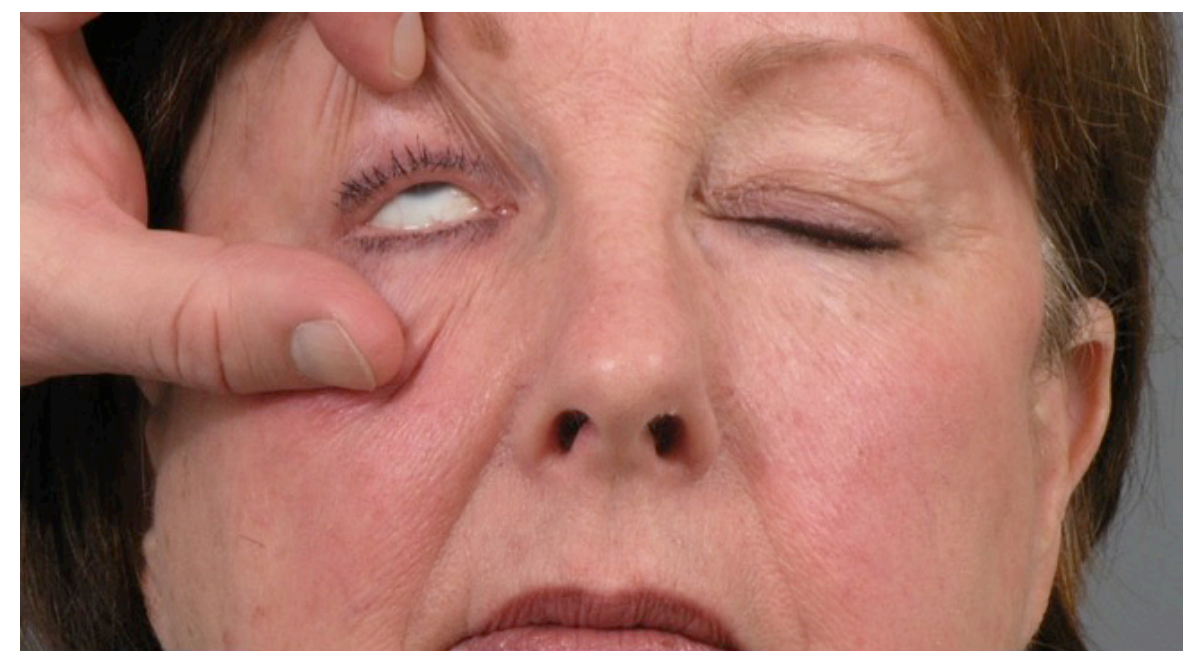

Figure 12. Bell's test showing a good superior position of the eye on forced opening
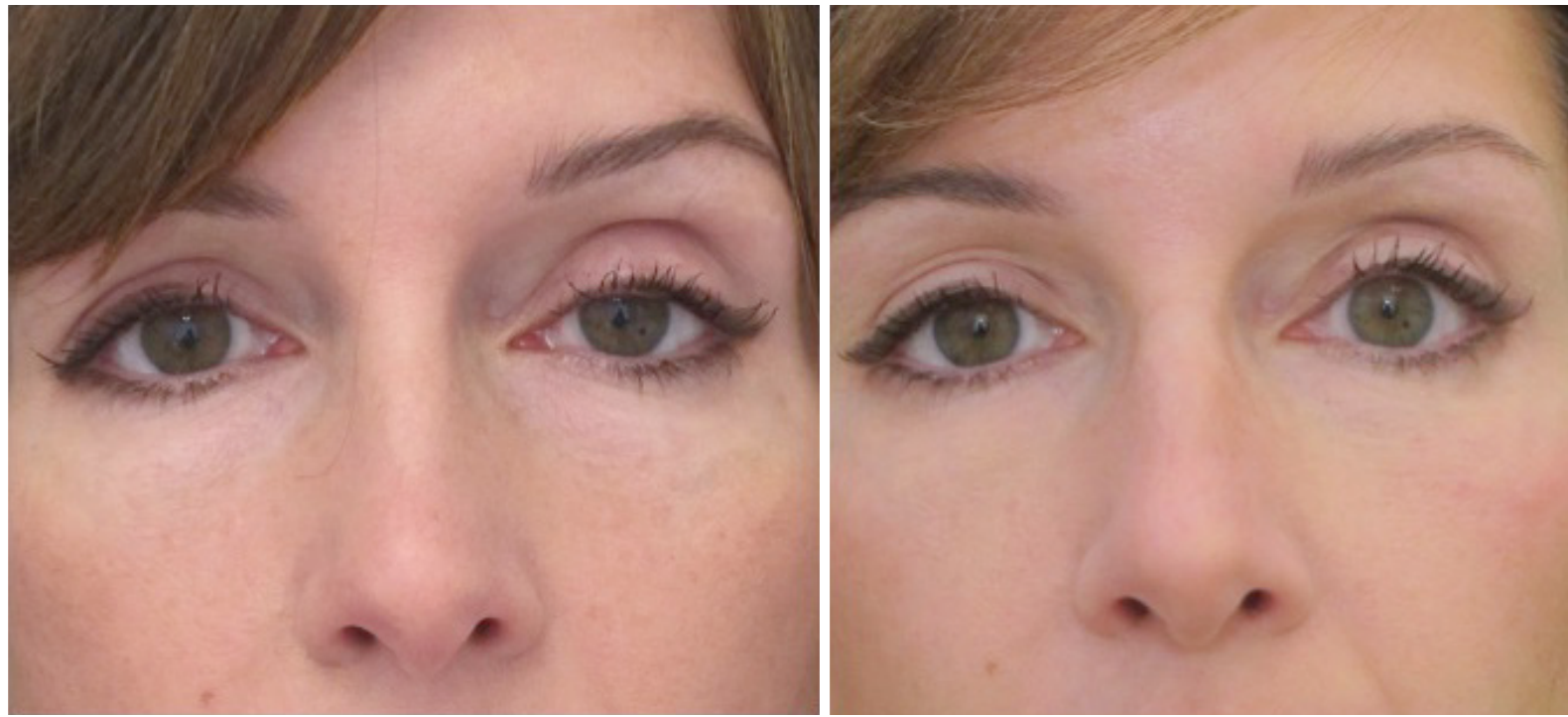

Figure 13. A patient with left upper lid ptosis with a high lid crease and elevation of the left brow for compensation

Next, the etiology of the patient's lid ptosis should be determined as an extrinsic factor, such as brow ptosis and pseudoptosis, or dermatochalasis, which can also give the appearance of a ptotic lid. In the case of brow ptosis, the brow rests below its normal position, which is at the level of the supraorbital rim in men or up to one centimeter above the rim in women. Attention must be paid to the presence of transverse forehead rhytids and a unilateral elevated brow which is compensating for unilateral ptosis, as these may be an indication of compensated brow or lid ptosis [Figure 13]. Dermatochalasis is characterized by an excess of upper lid skin and soft tissue, which can cause pseudoptosis of the upper lid ${ }^{[6]}$. In the presence of true involutional lid ptosis, in addition to a low lid margin, other examination findings might include an elevated lid crease and thinned upper eyelid, signifying attenuation of the levator aponeurosis ${ }^{[7]}$.

There are many techniques for quantifying the degree of lid ptosis. First, the margin reflex distance 1 is the distance from the central corneal light reflex to the upper eyelid margin. Normally, this measurement is between $3-4 \mathrm{~mm}$ and is reduced in patients with upper lid ptosis. In the worst cases, the upper lid may partially obstruct the corneal light reflex. Next the measurement of the palpebral fissure, or the eyelid 

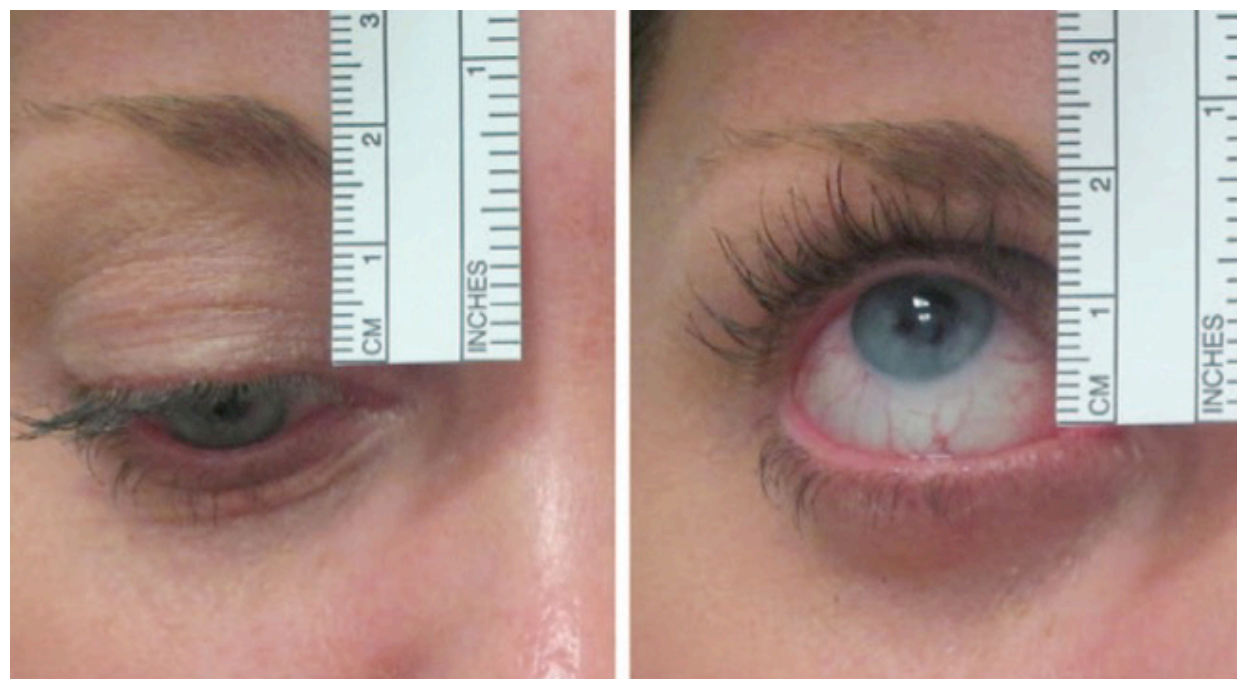

Figure 14. Measurement of levator function by the excursion distance from downgaze to maximum upgaze

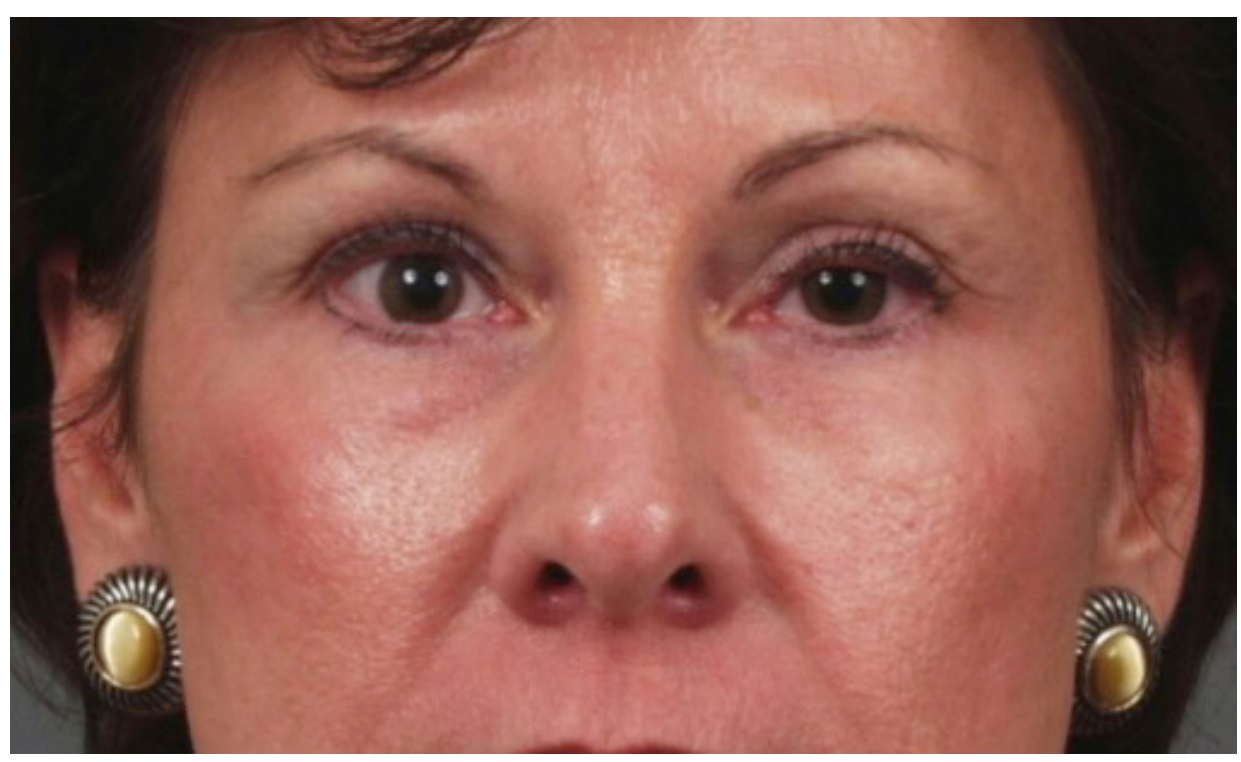

Figure 15. An example of a patient with left upper lid ptosis and right upper lid retraction caused by Herring's Law

aperture measured from the lower to upper lid margin in the midpupillary axis, should normally be 8-10 mm. However, in patients with ptosis, it is reduced. Additionally, lid crease height measures the distance from the lash line to the lid crease. Due to the dehiscence of the levator from the tarsus in patients with involutional ptosis, the lid crease height is often elevated in these patients. Finally, levator function is measured as the amount of lid excursion from extreme upgaze to extreme downgaze [Figure 14]. In patients with concomitant brow ptosis, this finding must be quantified while stabilizing the brow on the supraorbital rim. Normal excursion should be greater than $10 \mathrm{~mm}$. Patients with involutional ptosis characteristically have preserved levator function. Importantly, asymmetries in the degree of ptosis should be noted, as correction of only the more ptotic eye will result in worsening contralateral ptosis postoperatively due to equal bilateral innervation of the levator by cranial nerve III - a phenomenon known as Herring's Law [Figure 15]. It is generally recommended to patch the ptotic eye for $5 \mathrm{~min}$ and the contralateral lid will usually descend, and therefore, bilateral ptosis repair is recommended ${ }^{[3]}$. 


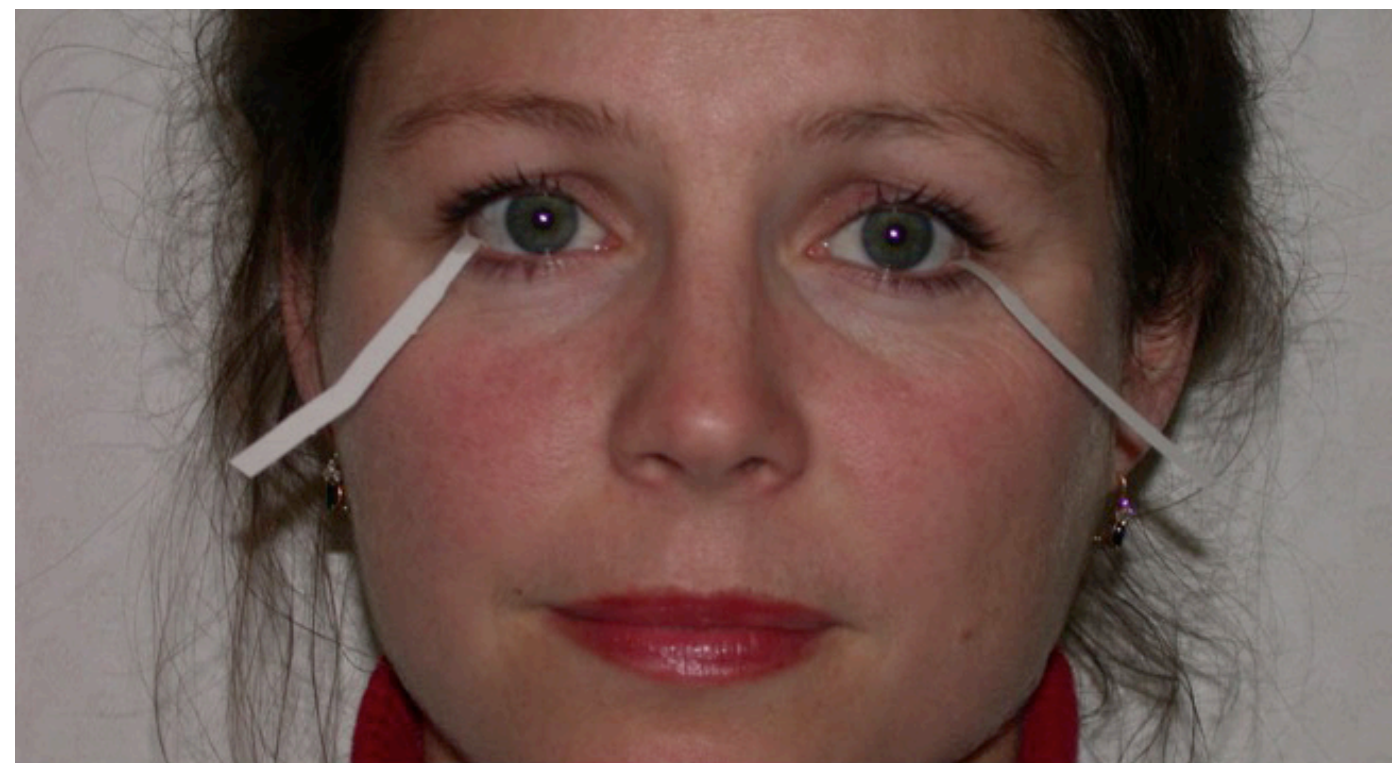

Figure 16. To assess the presence of dry eye, an anesthetized Schirmer's test is performed prior to surgery. One would be more conservative during upper blepharoplasty in a patient with poor tear production

In addition to eliciting a history of dry eye symptoms, these findings can also be quantified during the physical examination. The Schirmer test is performed by placing a piece of filter paper inside the lateral lower lid margin and waiting for five minutes [Figure 16]. At this point in time, a less than 5-mm length of wetting is used to diagnose dry eyes, while greater than $10 \mathrm{~mm}$ is normal. Positive findings would indicate the need for treatment of dry eye symptoms pre- and postoperatively ${ }^{[8]}$. Another useful test to consider prior to a posterior approach, such as a Mullerectomy, is improvement of the eyelid position in the office with a phenylephrine test. If a patient has isolated 1-2 mm of ptosis and no other indications for surgery, Phenylephrine can be given to both eyes. If this corrects the ptosis, this subgroup of patients can be considered for a posterior approach.

Other protective mechanisms should be assessed to ensure adequate postoperative ocular protection. These mechanisms are critical, as all ptosis procedures decrease the capacity of the upper lid to close. Therefore, in addition to Bell's phenomenon, eyelid closure strength, corneal sensation, and ocular lubrication must be verified preoperatively ${ }^{[3]}$.

\section{OPERATIVE APPROACH}

\section{Basic considerations}

To address the needs of patients with lid ptosis, the surgeon treating these patients should be capable of performing a variety of types of ptosis repairs. As with most surgical problems, no single technique is best suited for all patients. Therefore, we will outline high-yield procedures that a surgeon treating patients with lid ptosis should have in his or her armamentarium. Ultimately, when deciding which ptosis repair to perform, the surgeon should consider the needs of the patient and which operation achieves the best results in his or her hands.

Upper eyelid surgery can be performed using either local or general anesthesia. Local anesthetic allows for patient participation in the assessment of upper lid function. However, it is important to note that local anesthetics may alter upper lid dynamics intraoperatively, complicating surgical decision making. In particular, epinephrine can stimulate the sympathetically innervated Müller's muscle, causing false lid elevation, and lidocaine can weaken the levator muscle, causing false lid depression. Therefore, a precise 


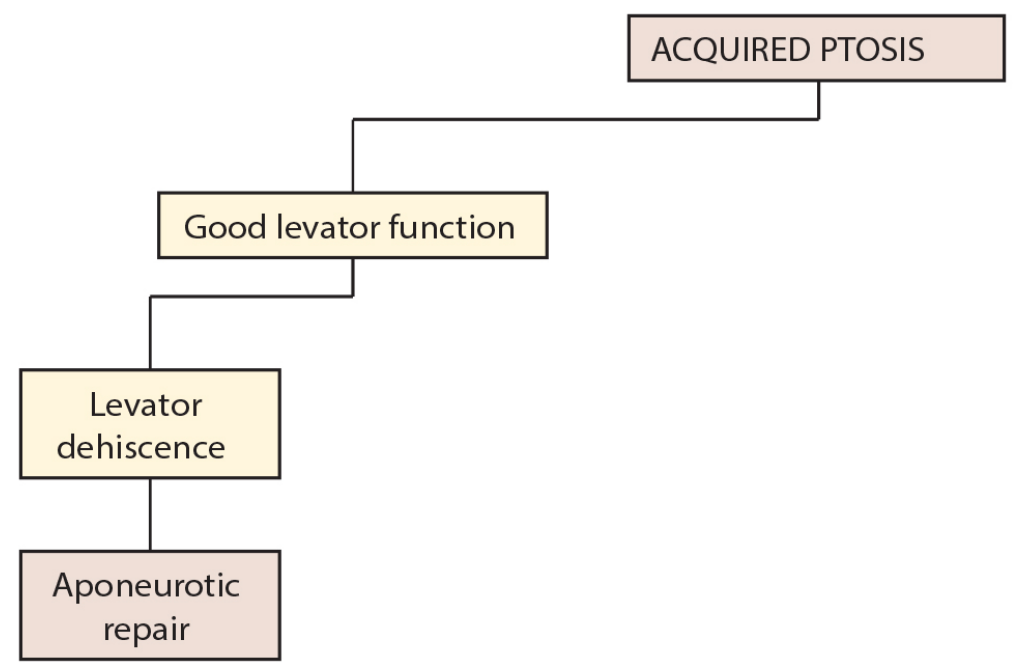

Figure 17. Brief algorithm followed for adults with acquired ptosis and good levator function

A

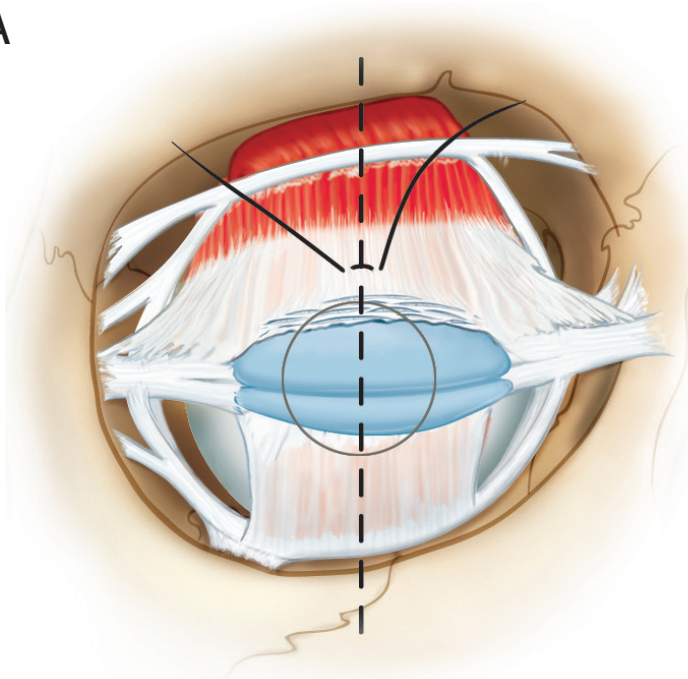

B

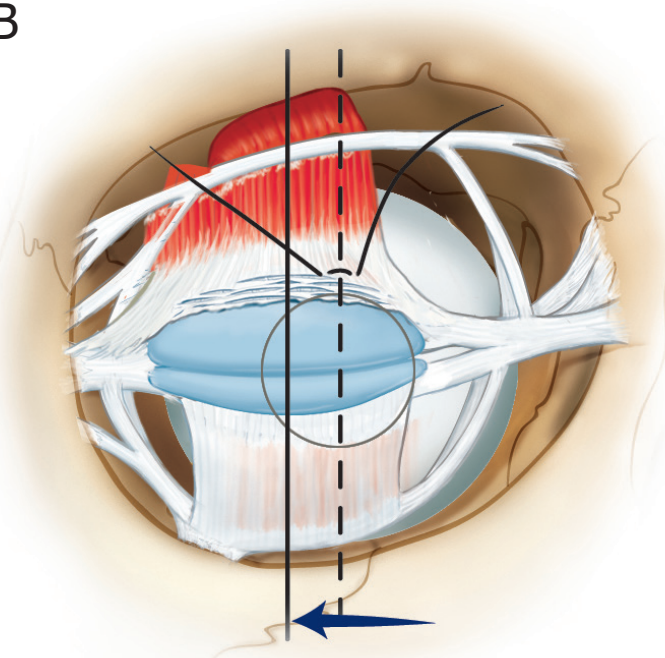

Figure 18. A: the circle marks the pupil and the vertical midline is drawn which is near the center of the tarsal plate border in the youthful lid; B: with aging and weakening of the medial horn of the levator, the levator and tarsal plate complex shift laterally. The ptosis suture still needs to be placed in the midline of the pupil

quantification of upper lid ptosis may be possible under either sedation or general anesthesia with or without patient cooperation ${ }^{[9]}$.

\section{Techniques}

\section{Levator aponeurosis repair}

The most common type of lid ptosis results from a dehiscence of the levator aponeurosis. Therefore, levator aponeurosis repair is the most common levator procedure performed [Figure 17]. In addition to the dehiscence of the aponeurosis and resultant downward migration of the tarsus, there is also a more pronounced attenuation of the medial horn of the levator aponeurosis, leading to a lateral migration of the tarsus [Figure 18] ${ }^{[10]}$.

The levator aponeurosis repair procedure is indicated in patients who have normal levator function but appreciable dehiscence of the aponeurosis, as evidenced by an elevated lid crease, a thinned upper 


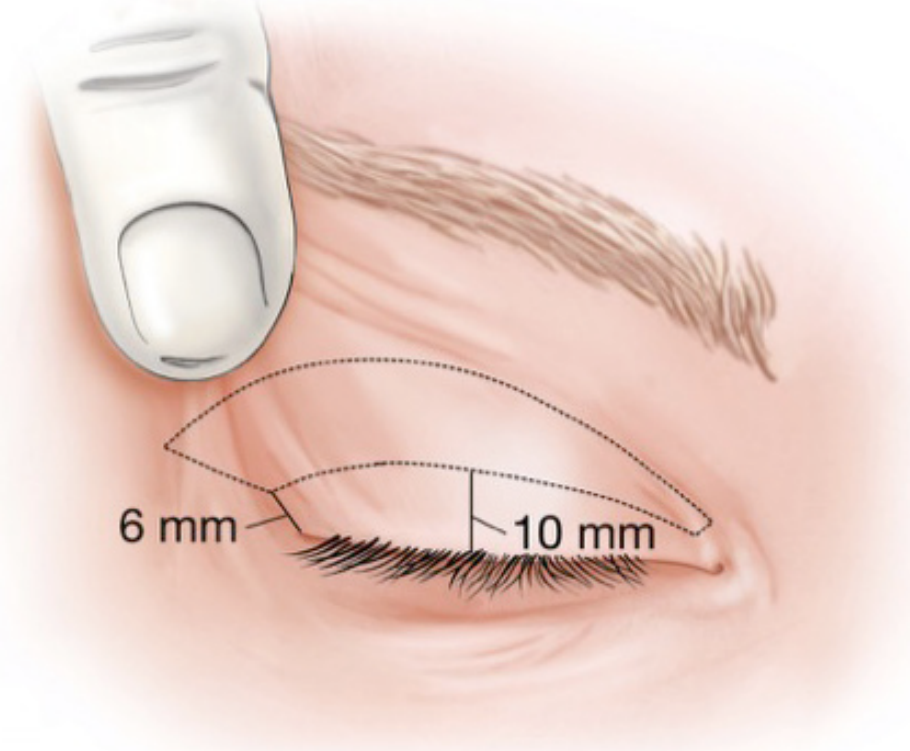

Figure 19. The approximate skin markings for tarsolevator advancement uses an anterior approach similar to an upper blepharoplasty
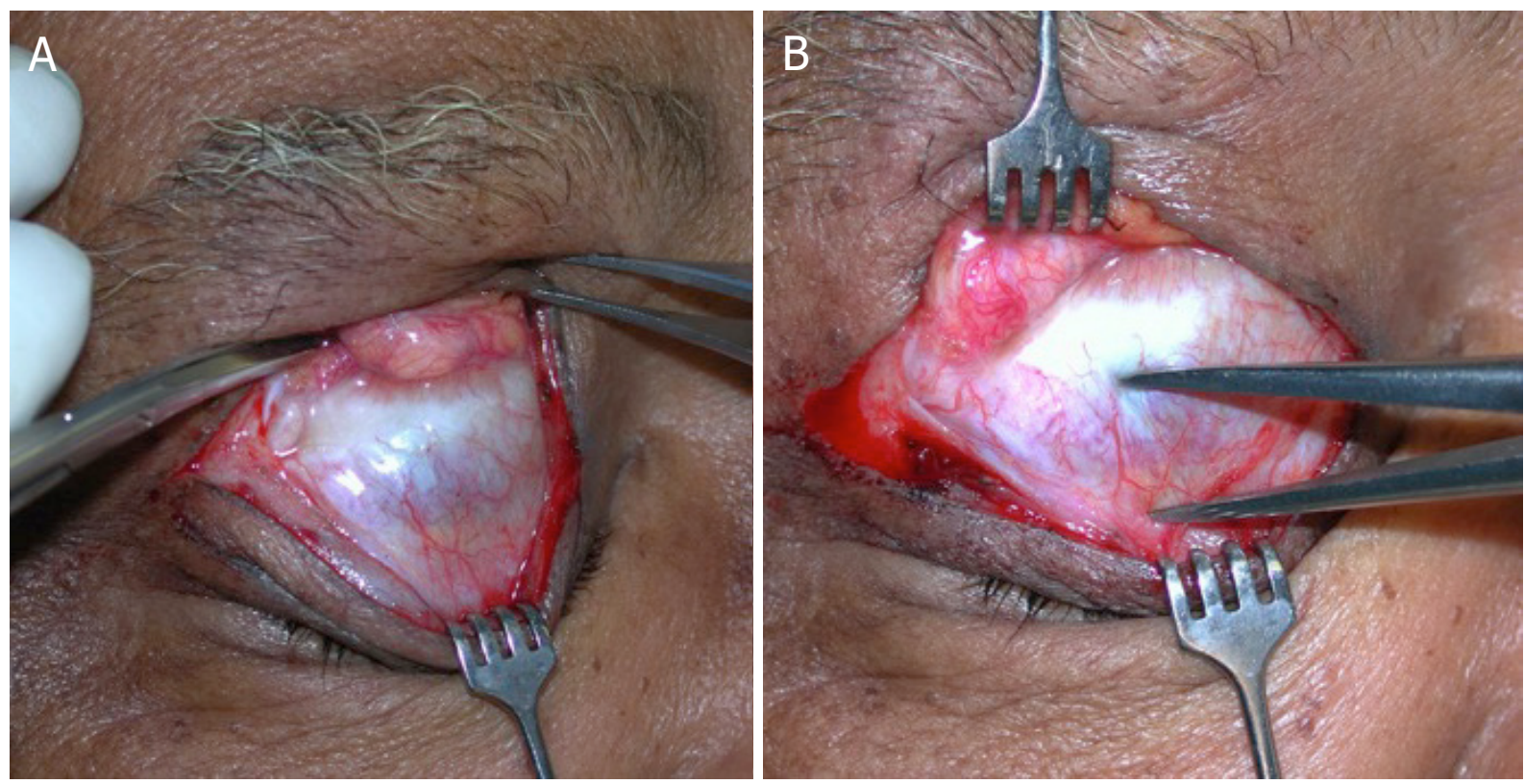

Figure 20. A: the dystrophic, thin levator is demonstrated; B: the calipers are used to show $10 \mathrm{~mm}$ of dehiscence from the tarsal plate to the levator aponeurosis

lid, and a visible corneal outline through the attenuated lid. The basis of this technique is restoring the levator aponeurosis to its normal anatomic position, which involves both superior and potentially medial repositioning ${ }^{[1]}$.

Skin markings for the levator aponeurosis repair are performed as in a standard upper lid blepharoplasty [Figure 19]. The lid crease is marked where visible or $8 \mathrm{~mm}$ above the margin in a male or $8-10 \mathrm{~mm}$ in a female. Once incisions are made, the skin and muscle flap are excised, along with orbital septum, to expose the preaponeurotic fat - a helpful landmark for the underlying levator aponeurosis. Once the preaponeurotic fat is retracted, the aponeurosis and musculoaponeurotic junction are visible [Figure 20]. 

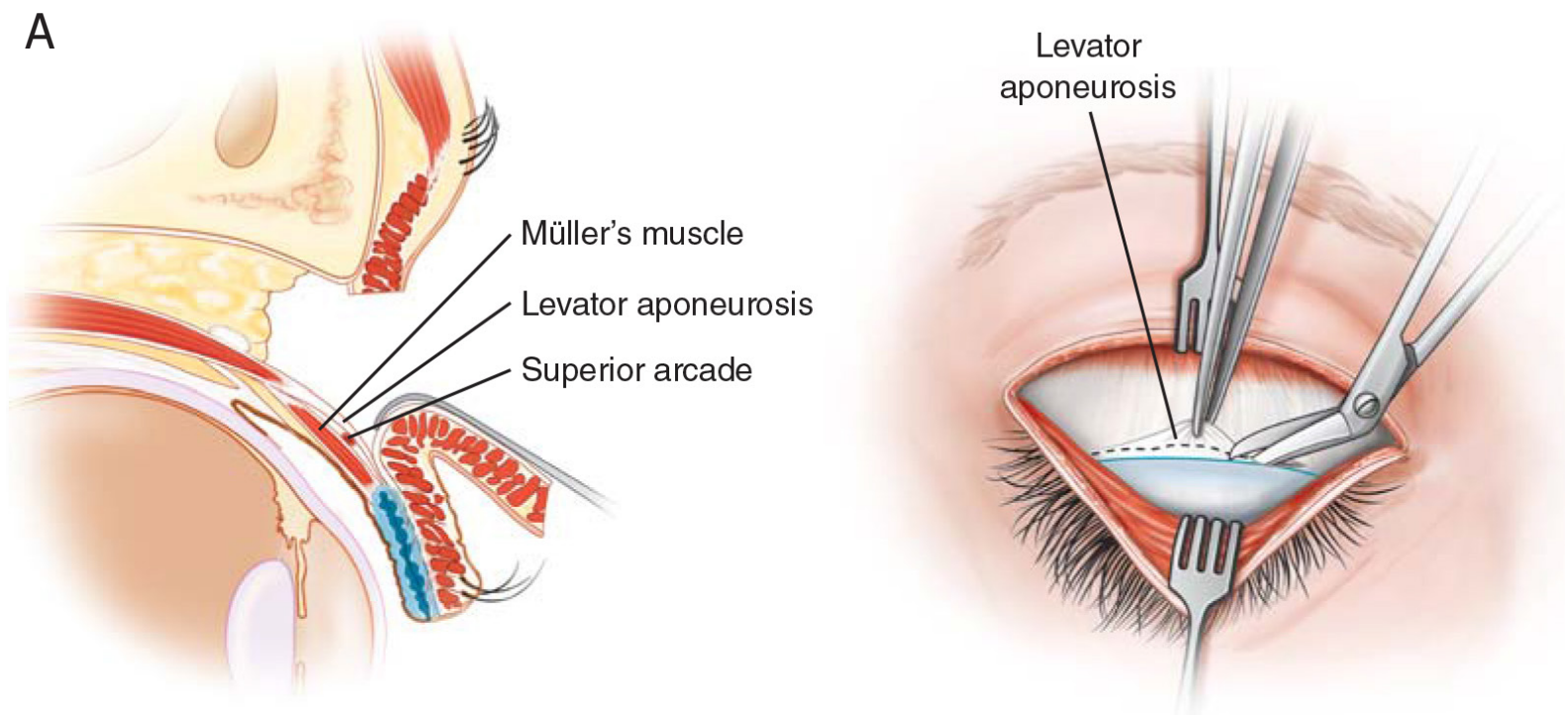

B

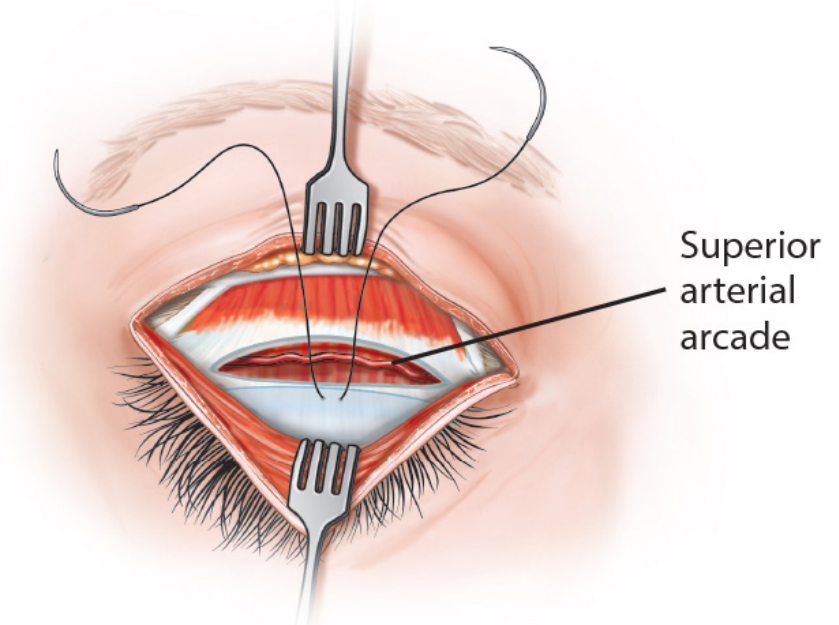

Figure 21. A: tarsolevator advancement is generally performed by initially dividing the central levator aponeurosis, sparing the medial and lateral horns; B: once the levator aponeurosis is elevated off Mueller's muscle, avoiding the superior arcade, a double-armed 6-0 silk single suture is placed through the midline of the superior tarsal plate and through the musculoaponeurotic junction with an adjustable knot anteriorly

An incision is made through the aponeurosis down to the superior border of the tarsus, and the aponeurosis is dissected off of the underlying Müller's muscle [Figure 21, Video 1] ${ }^{[1]}$.

At this point, the amount of aponeurotic repair must be determined, which can be done through patient cooperation and intraoperative adjustment or, more precisely, through the senior author's preferred threestep technique. This technique involves first approximating the superior border of the tarsal plate and the musculoaponeurotic junction with a single, double-armed suture at the midpupillary line in a horizontal mattress fashion, verifying that the suture has not passed through the underlying conjunctiva. Next, the suture is adjusted to ensure a symmetric amount of gapping between the two sides. Finally, the tension of the repair is tested by pulling down the lashes to close the lid and releasing to confirm equal velocity of snapback between the two sides [Video 2]. This particular technique has several advantages, including the ability to perform it under general anesthesia and combine it with other aesthetic operations, the exclusion of local anesthetic agents, which may confound the degree of ptosis repair, and the elimination of the need for patient cooperation. Other techniques of quantitating the degree of ptosis repair include the cookie 


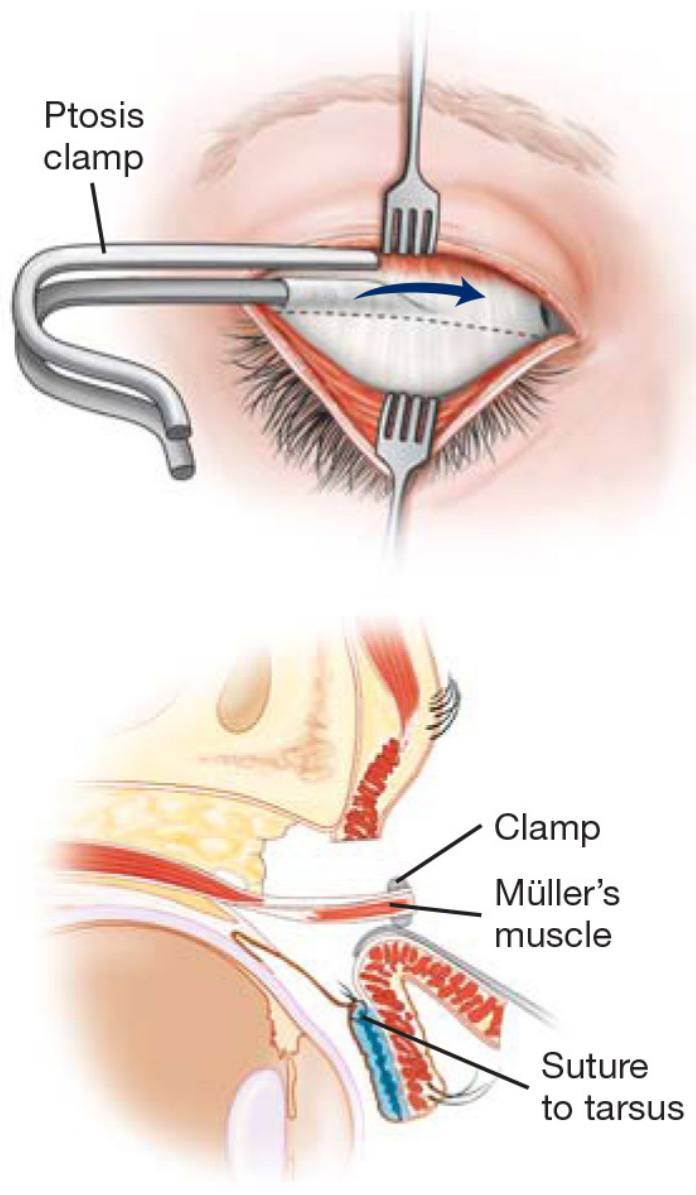

Figure 22. In congenital ptosis, primarily a ptosis clamp can be used to perform levator Mueller's resection

cutter technique (measuring an exact amount of tissue to be removed) and the voluntary cooperation technique. In our experience, these methods are not recommended as they have been associated with higher rates of revision ${ }^{[9]}$.

If the ptosis is unilateral, careful consideration must be given to ensure that this diagnosis is correct, as there is often a lesser degree of contralateral ptosis that might go untreated. If this is not the case, unilateral ptosis can be corrected solely with approximation of anatomic landmarks ${ }^{[9]}$. Levator plication is a simple but inaccurate technique for ptosis repair and is not recommended or used by the senior author.

Levator-Müller's muscle resection

Resection of both the levator and Müller's muscle is generally indicated in patients with decreased levator function secondary to scarring or muscle dysfunction. However, for this technique to be effective, there must be some residual levator function ${ }^{[1]}$.

The procedure begins with an identical marking and initial dissection to the levator aponeurosis repair. However, this approach also includes an exposure of Müller's muscle and dissection of the levator from its connective tissue attachments (lateral horn and Whitnall's ligament) to increase its stretch [Figure 22] ${ }^{[1]}$.

In this type of repair, the resection can be quantified by measuring the amount of levator resected or the amount of eyelid gapping, though the eyelid gapping technique has proven more predictable [Figure 23]. 


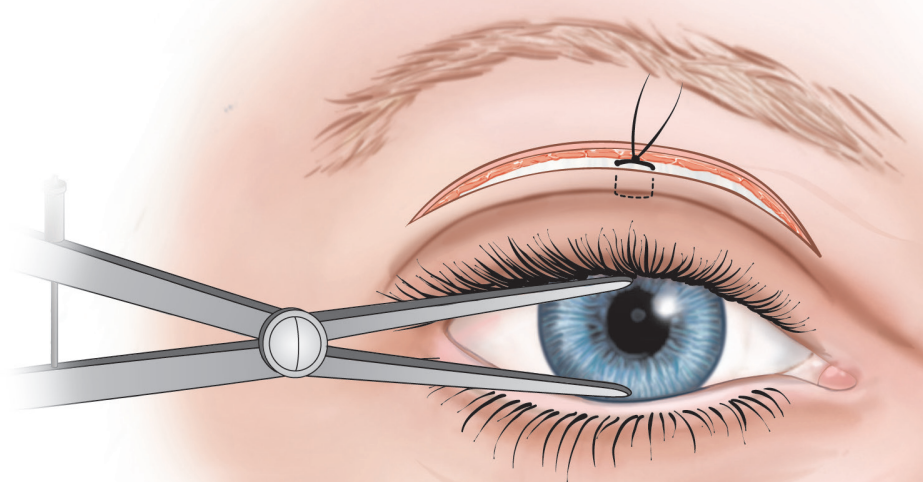

Figure 23. After ptosis repair while the knot is still adjustable, the gap between the upper and lower lid is measured with calipers and can be compared from each side

The degree of gapping is determined by the amount of levator function - poorer levator function requires a more aggressive repair. The central lifting suture is then placed in the tarsal plate and the double arms are run through the muscle complex near Whitnall's ligament and tightened to the desired gapping. This tightening generates redundant levator and Müller's muscle, which is subsequently resected. Additional sutures can then be placed to create a smooth contour ${ }^{[1]}$.

\section{Tarsoaponeurectomy}

The tarsoaponeurectomy allows for a less precise anatomic resection of upper lid structures. It is indicated in patients who have scarring of anatomic planes due to trauma or prior surgery but still maintain excellent levator function. It is typically used as a last resort when anatomic planes cannot be identified ${ }^{[1]]}$.

The operation is performed by making an upper lid crease incision and exposing the tarsal plate and levator aponeurosis. A predetermined amount of full thickness resection is performed, usually amounting to $0-2 \mathrm{~mm}$ plus the amount of ptosis [Figure 24] $]^{[1]}$.

\section{Tarsomullerectomy/Fasanella-Servat}

This procedure involves a posterior approach resecting Müller's muscle with or without tarsus. An advantage of this approach is the avoidance of a skin incision and preservation of lid contour ${ }^{[12,13]}$.

Following a skin and muscle resection where indicated, the operation proceeds by everting the lid and using two small mosquito clamps to grasp the tarsus and conjunctiva [Figure 25]. The amount of tissue to grasp within the clamp is determined by the degree of ptosis and amount of desired lift. Sutures are placed and passed through the eyelid $1 \mathrm{~mm}$ beneath the clamp carefully passing each suture through the previous suture hole to effectively bury the suture and prevent corneal irritation. Next, the excess conjunctiva, Müller's muscle and tarsus are excised and the sutures are externalized and tied down for removal around 1 week postoperatively. Essentially, this procedure attaches a disinserted levator to a shortened tarsus ${ }^{[1]}$. 

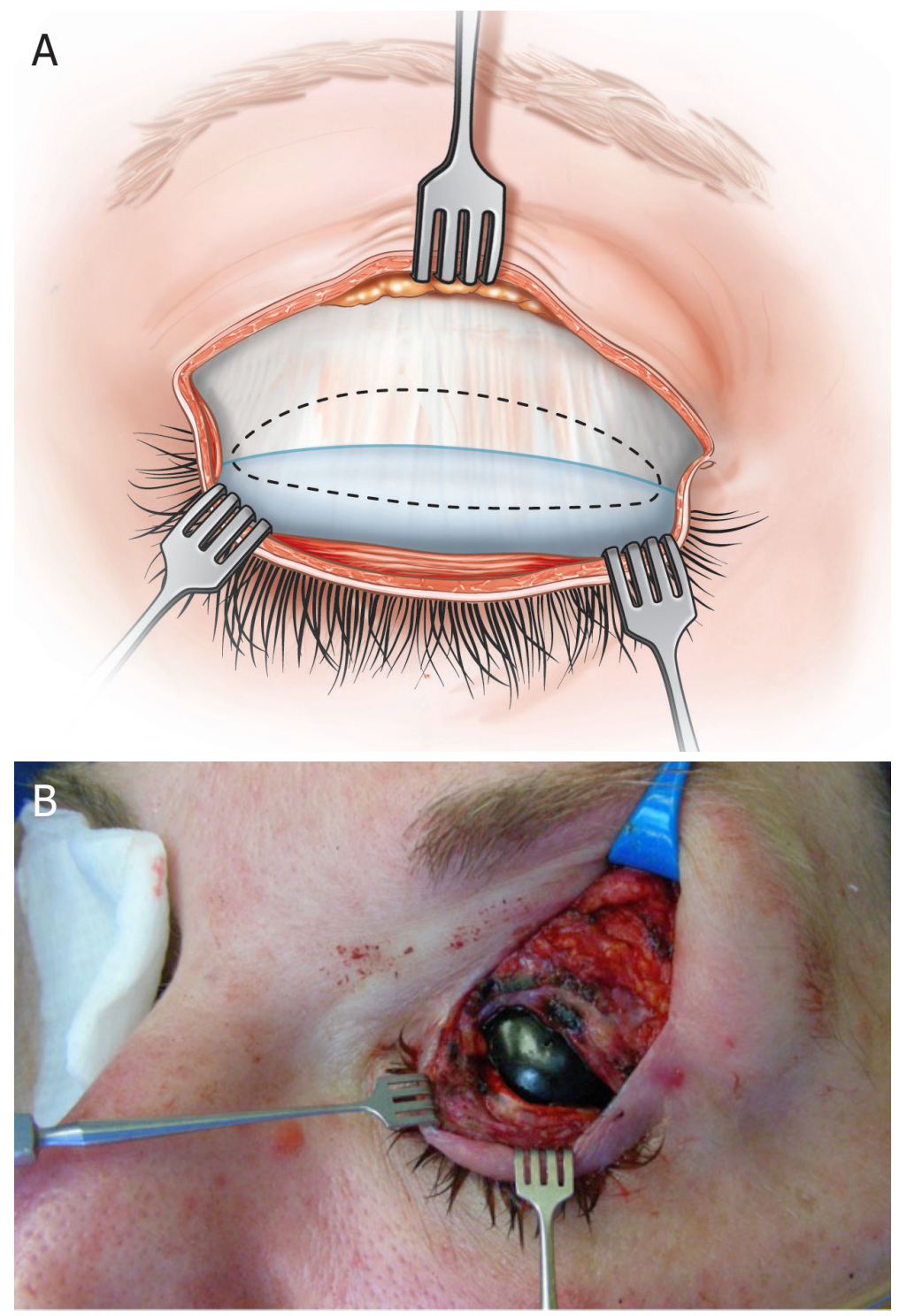

Figure 24. A: markings on the levator aponeurosis and superior tarsal plate for excision of full thickness tissue during a tarsoaponeurectomy; B: the black eye protector can be seen during a tarsoaponeurectomy

\section{Frontalis suspension}

Frontalis procedures circumvent the levator when elevating the upper lid and are therefore indicated in patients with poor levator function. Typically, frontalis suspension is indicated in patients with congenital ptosis $^{[1]}$.

The operation can be performed with prosthetic or autologous material. Fascia lata is most commonly used in the adult patient with acquired ptosis. Silicone rods are reserved for pediatric patients who do not have sufficient donor site fascia ${ }^{[1]}$.

The technique begins with a single brow incision in the midpupillary line until the frontalis is identified. Next, a lid crease incision is made, and the superior edge of the tarsal plate is exposed to allow for sutures to be tied over a strand of suspensory material. This material is then passed deep to the orbicularis until it reaches the frontalis, generating a pentagonal configuration by placing the lateral and medial sutures inferiorly outside of the limbus [Figure 26]. The lid crease is closed prior to tightening the suspensory material at the brow level ${ }^{[1]}$. 


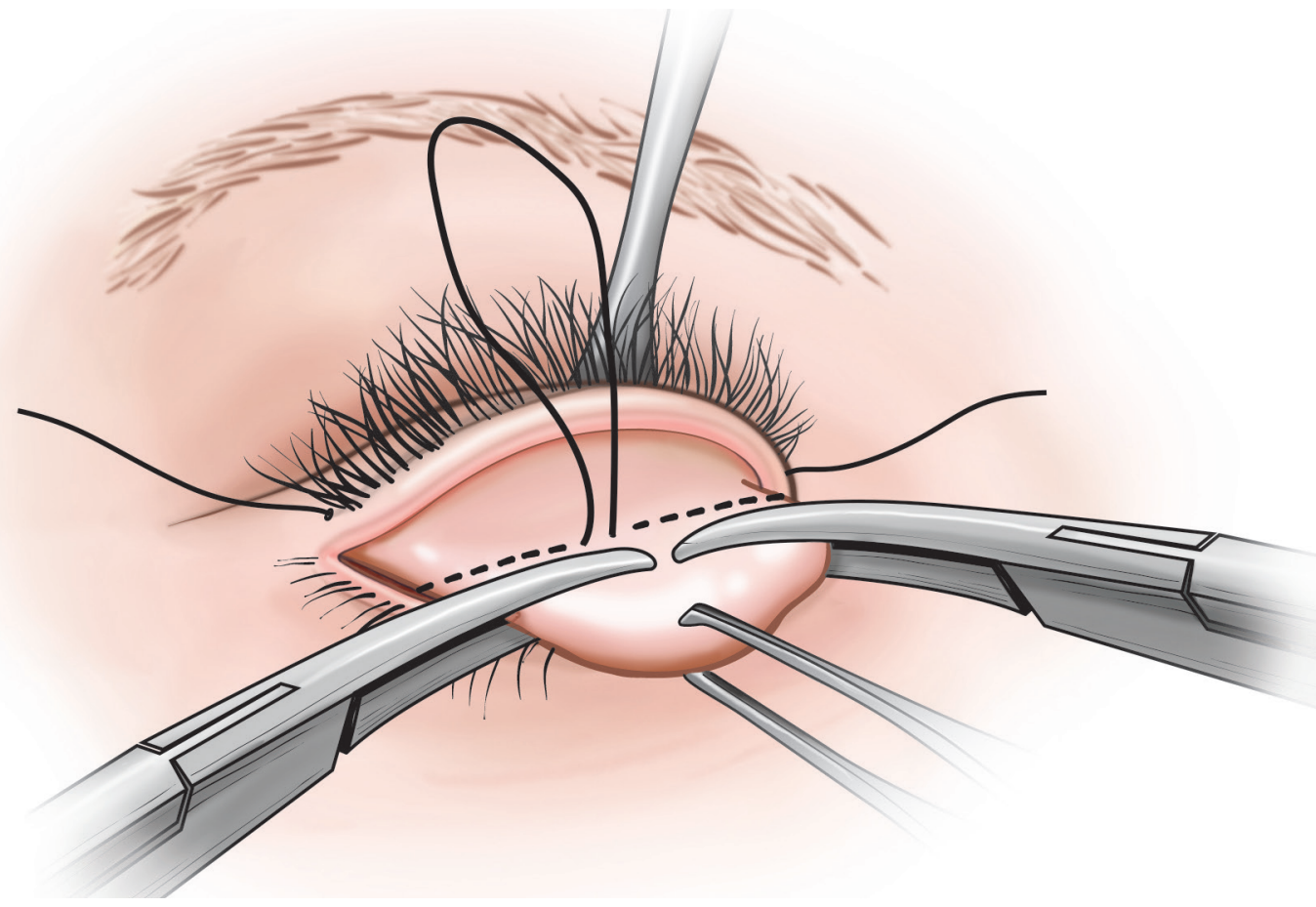

Figure 25. Two small clamps are used in a posterior approach while the tarsal plate and Mueller's muscle are oversewn and resected to approximate the amount of tissue removed to correct the degree of ptosis
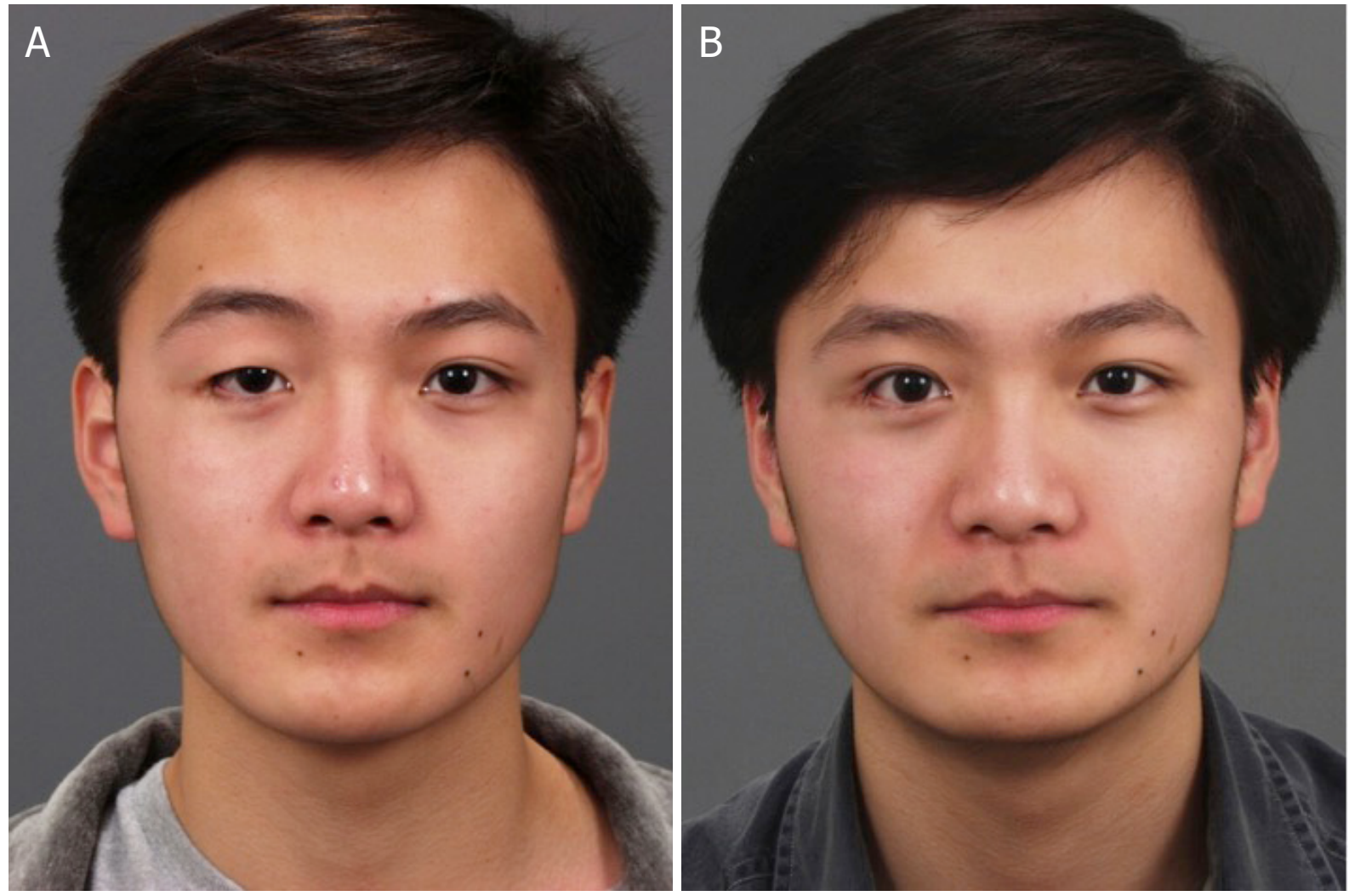

Figure 26. A: a young Asian man with asymmetrical creases and right upper lid ptosis; B: shown after surgery on the right eyelid only to create $a$ fold and similar height crease 


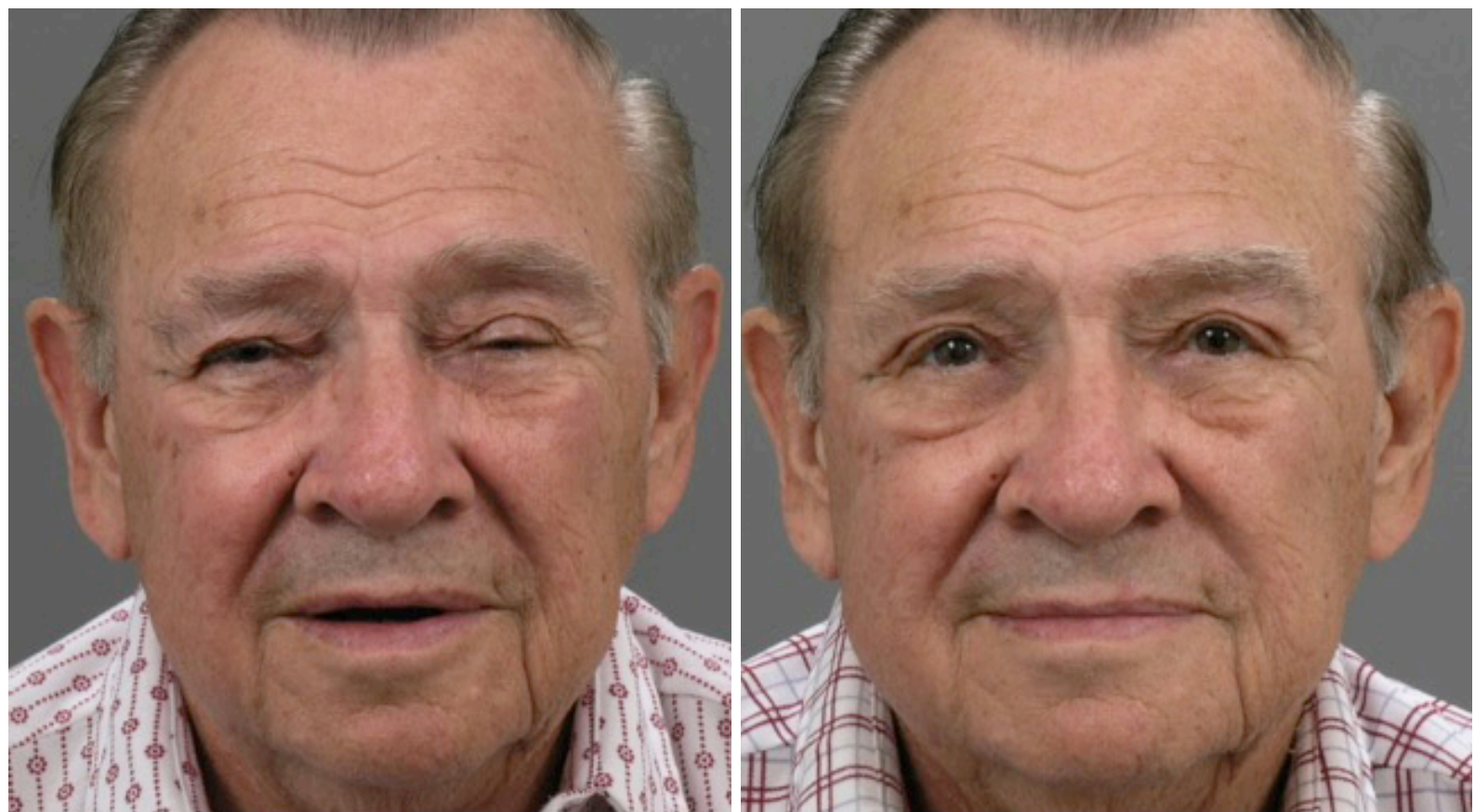

Figure 27. An elderly patient demonstrates bilateral ptosis with a high lid crease on the left shown before and after tarsolevator advancement

\section{Postoperative management}

Patients should be instructed to sleep with their head elevated and to apply cold compresses. Lubricating eye drops or ointment should be prescribed and used liberally. Most surgeons also prescribe a topical ointment containing antibiotics or steroids to be applied to the lid incision. Sutures are normally removed within one week postoperatively.

\section{OUTCOMES}

\section{Postoperative results}

Although there are no randomized controlled comparison studies on ptosis repair techniques, there are studies reviewing the revision rates of individual techniques for involutional ptosis repair [Figures 26-31]. The outcomes and techniques in these studies are highly variable ${ }^{[8]}$. However, one consistent finding was the higher rate of revisions in patients with more severe preoperative ptosis and fibrosis ${ }^{[14]}$. Therefore, patients with more severe ptosis should be counseled about this risk preoperatively. The most important consideration is ultimately which technique is most reliable in each surgeon's own hands.

\section{Complications}

Overcorrection or undercorrection

Rates of overcorrection and undercorrection vary on the basis of repair technique. Undercorrection is best treated with surgical revision if the degree of asymmetry or ptosis is sufficient to warrant operative intervention. The timing of surgical revision should allow for adequate resolution of acute postoperative swelling, but should also occur prior to the formation of significant scarring that would make identification of anatomic planes difficult.

If the eyelid is slightly overcorrected, as evidenced by incomplete lid closure or scleral show, this finding can oftentimes be corrected by stretching the lid downward [Figure 32]. Traction stretching can be performed while the patient is awake and should be initiated within the first postoperative week. If this 

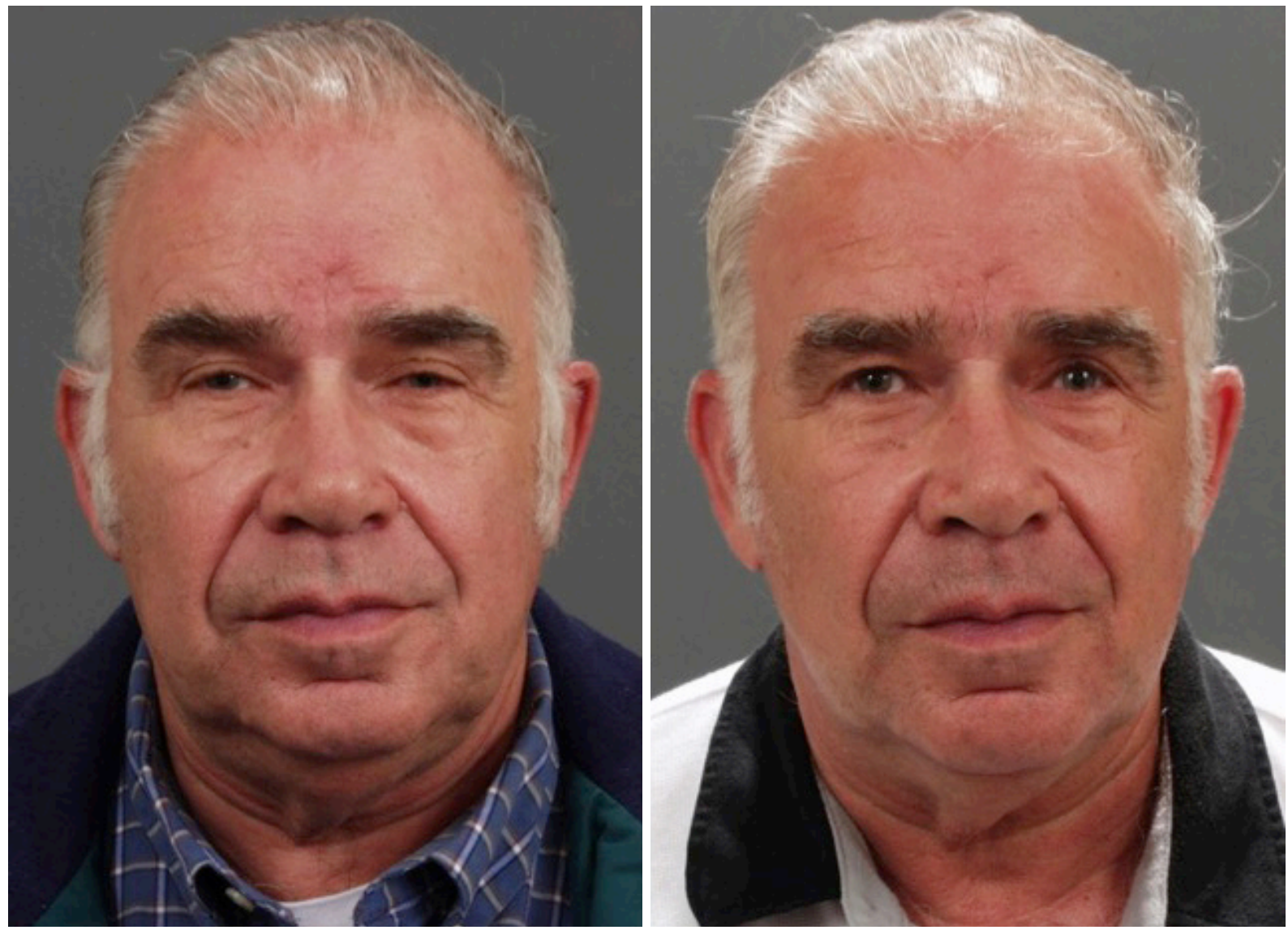

Figure 28. An elderly male with poor but adequate levator function before failed silicone slings were removed and an aggressive tarsolevator advancement was performed
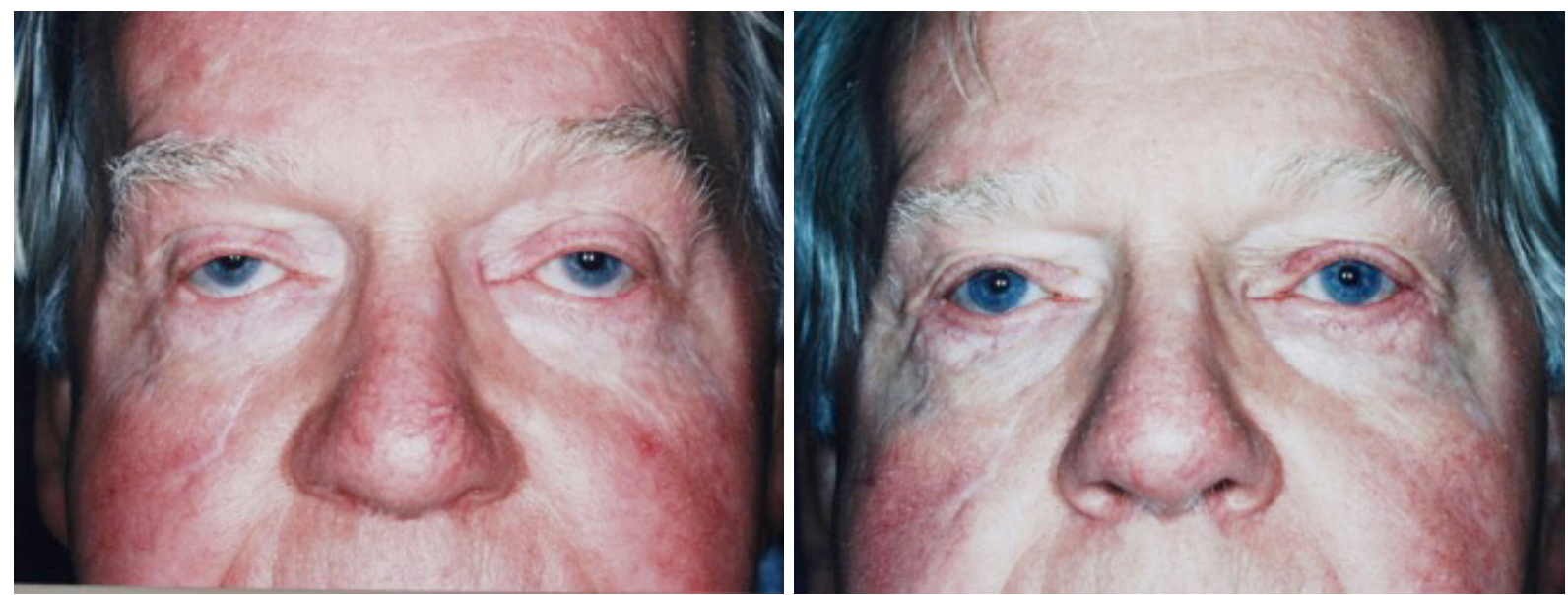

Figure 29. An elderly male with bilateral upper lid ptosis and lower lid ectropion from tarsoligamentous laxity shown before and after bilateral tarsolevator advancement and bilateral lateral canthoplasties

is unsuccessful, lid stretching can also be performed under local anesthesia in the early postoperative period $^{[2]}$. Patient dissatisfaction is higher in the aesthetic patient and can be upwards of $25 \%$. Reassurance and time, as well as massage lid stretching exercises, are often used. Unless overcorrection is felt to be a technical problem that can be fixed with immediate surgery at one week, the senior author recommends 

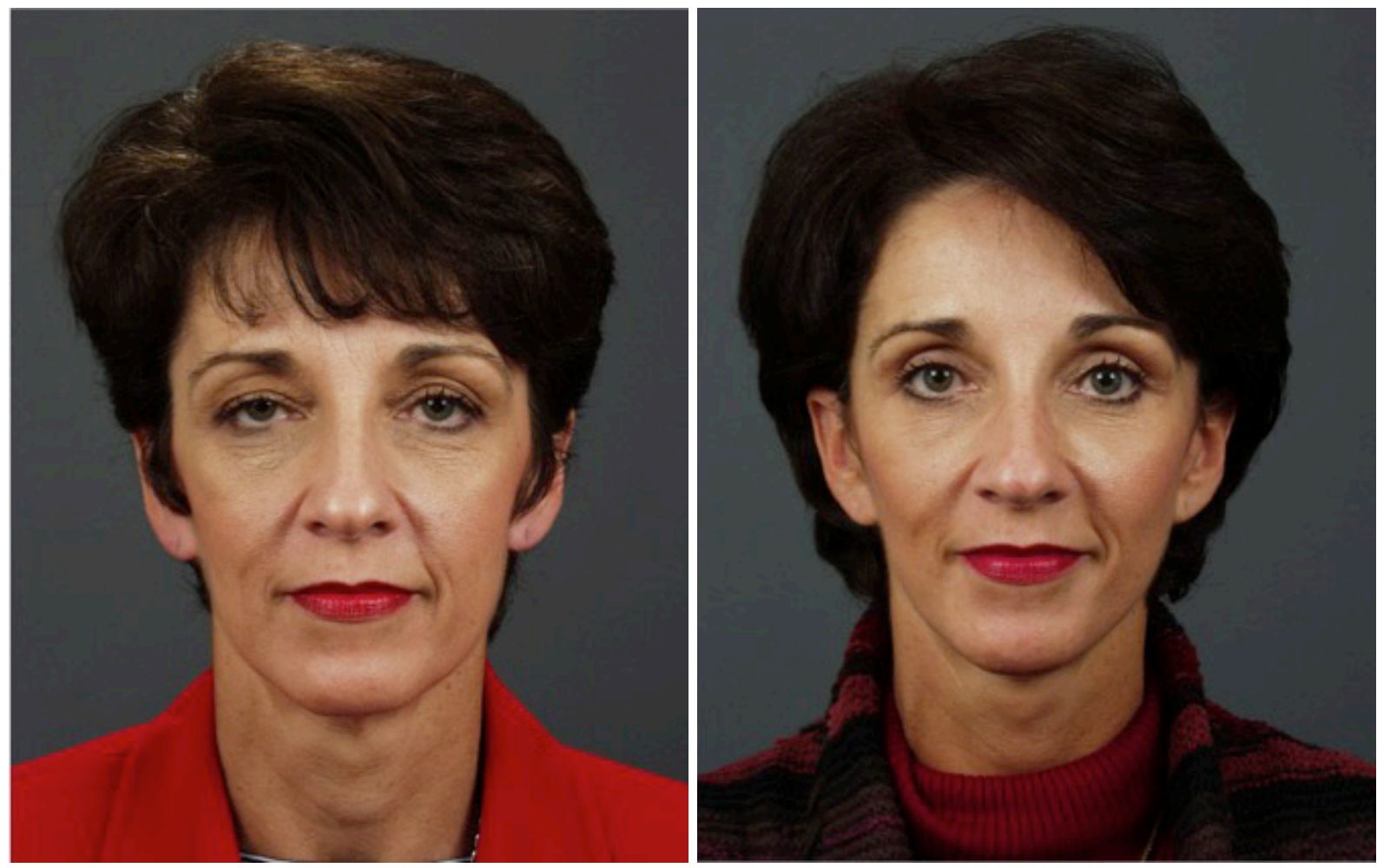

Figure 30. A cosmetic patient who felt she looked tired before and after tarsolevator advancement. Lower blepharoplasty, and facelift
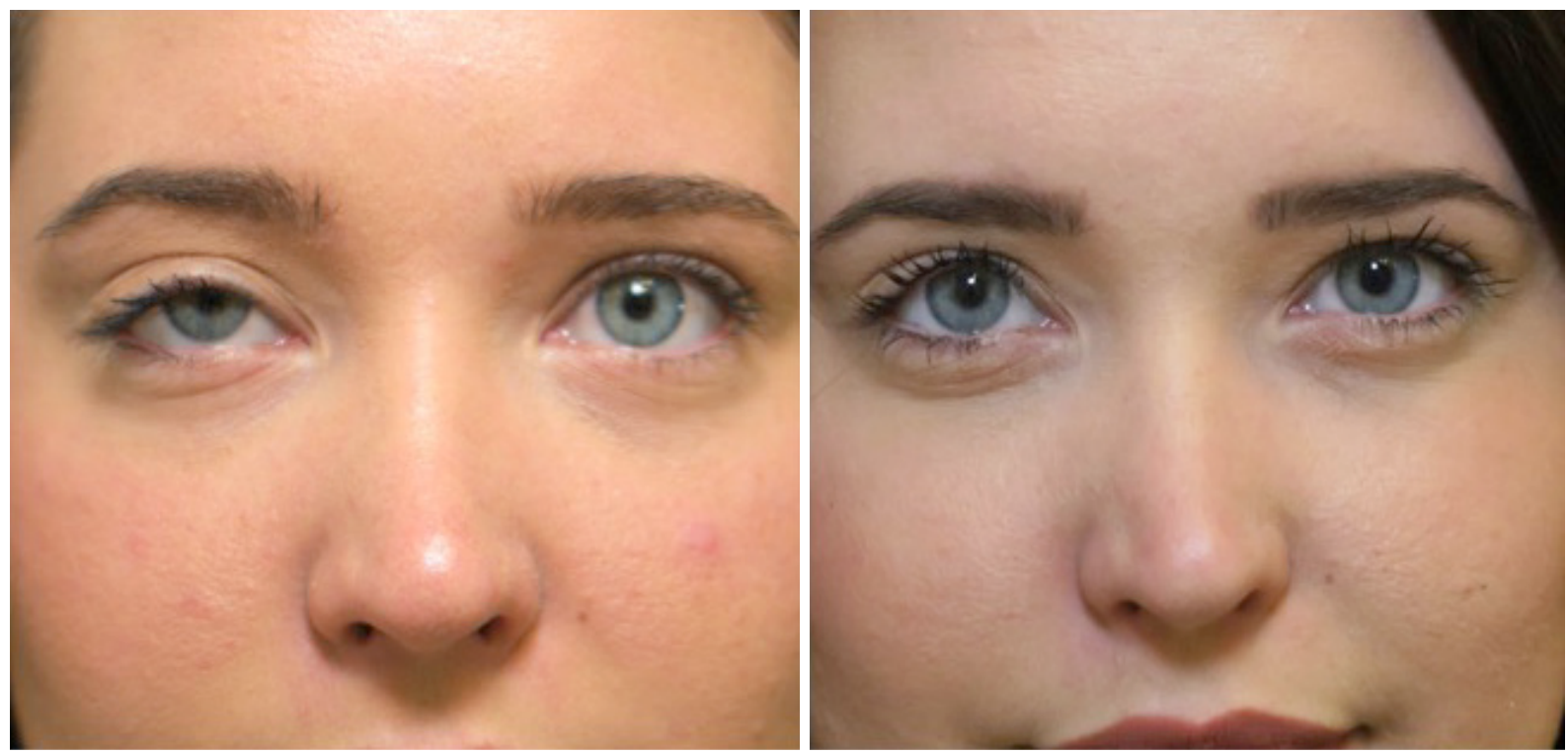

Figure 31. A young woman with congenital ptosis and good levator function after right tarsolevator advancement

always trying to overcorrect by a millimeter and having the patient stretch the lid if needed and waiting six months before revision surgery is performed.

\section{Ocular injury}

Every attempt should be made intraoperatively and postoperatively to protect the globe from ocular injury. Corneal protectors should be used, and importantly, the integrity of the surface that contacts the cornea 

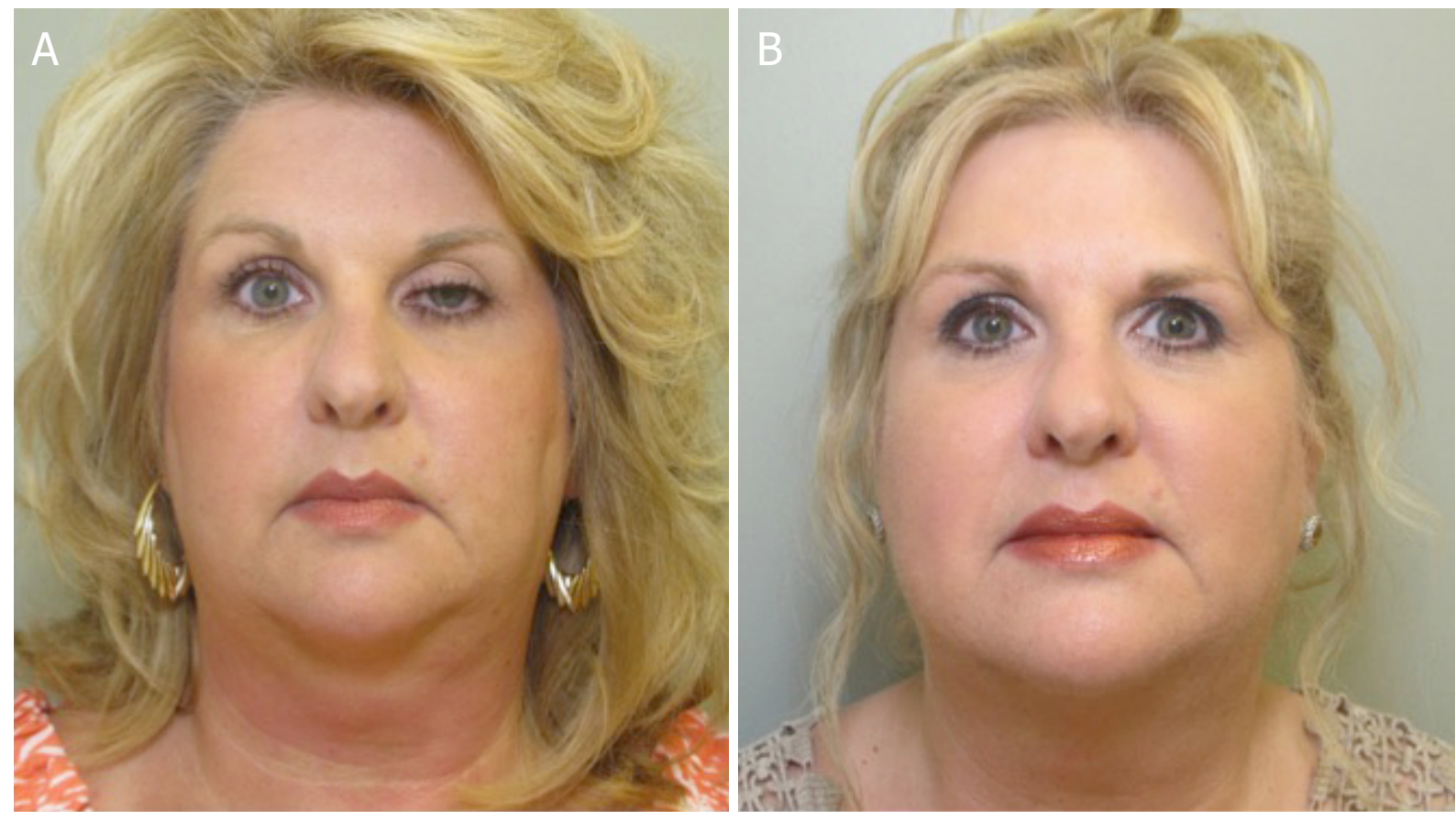

Figure 32. Patient with acquired left ptosis after left upper lid hematoma treated conservatively for a year (A). She had left tarsoaponeurectomy and was slightly overcorrected, which can easily be treated with downward lid massage (B).

should be verified prior to application. Postoperatively, adequate ocular lubrication should be ensured if lid closure is incomplete. Should an ocular injury occur, diagnosis is critical. Once a diagnosis is made, ophthalmologic referral is necessary.

\section{Xerophthalmia}

Transient dry eyes are a common finding following blepharoplasty with or without ptosis repair. However, if not appropriately treated, patients may suffer long-term morbidity. Lubricating eye drops and ointments should be prescribed. In more severe cases, patients can be prescribed a cyclosporine ophthalmic emulsion (i.e., Restasis; Allergan, Inc., Irvine Calif.) to stimulate tear production ${ }^{[15]}$.

\section{CONCLUSION}

With periorbital rejuvenation and blepharoplasty being a common request among aesthetic surgery patients, it is critical that the plastic and oculoplastic surgeon understand the preexisting conditions and potential complications that will affect the ultimate postoperative result. Commonly, patients presenting for blepharoplasty also have blepharoptosis. Failure to diagnose and treat lid ptosis will result in a less than ideal result and a dissatisfied patient. In this article, we reviewed the preoperative workup, the operative approach, and the postoperative management of concomitant blepharoptosis. By comprehensively addressing all age-related periorbital changes, the aesthetic plastic surgeon can expect to enjoy optimized results and satisfied patients.

\section{DECLARATIONS}

\section{Authors' contributions}

Manuscript drafting: Farber SE

Manuscript revisions, figures, videos: Codner MA 


\section{Availability of data and materials}

The data supporting our findings can be found stored securely in the office of Mark Codner, MD Plastic Surgery.

\section{Financial support and sponsorship}

None.

\section{Conflicts of interest}

All authors declared that there are no conflicts of interest.

\section{Ethical approval and consent to participate}

Not applicable.

\section{Consent for publication}

Written consent for publication was obtained for all images and videos.

\section{Copyright}

(c) The Author(s) 2020.

\section{REFERENCES}

1. Periorbital and eyelid anatomy. In: Codner MA, McCord DC, editors. Eyelid and periorbital surgery. 2nd ed. New York: Thieme; 2017. pp. 3-52.

2. Upper lid blepharoplasty. In: Codner MA, McCord DC, editors. Eyelid and periorbital surgery. 2nd ed. New York: Thieme; 2017. pp. 229-56.

3. Jindal K, Sarcia M, Codner M. Functional considerations in aesthetic eyelid surgery. Plast Reconstr Surg J 2015;134:1154-70.

4. Ptosis: evaluation and treatment. In: Codner MA, McCord DC, editors. Eyelid and periorbital surgery. 2nd ed. New York: Thieme; 2017. pp. 591-657.

5. Trussler AP, Rohrich RJ. MOC-PSSM CME article: blepharoplasty. Plast Reconstr Surg J 2009;121:1-10.

6. Lambros V. Observations on periorbital and midface aging. Plast Reconstr Surg J 2007;120:1367-76.

7. Codner MA, Kikkawa DO, Korn BS, Pacella SJ. Blepharoplasty and brow lift. Plast Reconstr Surg J 2010;126:1-17e.5

8. Chang S, Lehrman C, Itani K, Rohrich RJ. A systematic review of comparison of upper eyelid involutional ptosis repair techniques: efficacy and complication rates. Plast Reconstr Surg J 2012;129:149-57.

9. McCord CD, Seify J, Codner MA. Transblepharoplasty ptosis repair: three-step technique. Plast Reconstr Surg J 2007;120:1037-44.

10. Jones LT, Quicken MH, Wobig JL. The cure of ptosis by aponeurotic repair. Arch Ophthalmol 1975;93:629-34.

11. McCord CD. External minimal ptosis procedure - external tarsoaponeurectomy. Trans Sect Am Acad Ophtalmol Otolaryngol 1975;79:683-6.

12. Putterman AM, Urist MJ. Müller's muscle-conjunctival resection. Arch Ophthalmol 1975;93:619-23.

13. Fasanella RM, Servat J. Levator resection for minimal ptosis: another simplified operation. Arch Ophthalmol 1961;65:493-6.

14. Codner MA. Discussion: a systematic review of comparison of upper eyelid involutional ptosis repair techniques: efficacy and complication rates. Plast Reconstr Surg J 2012;129:158-9.

15. Pacella SJ, Codner MA. Minor complications after blepharoplasty: dry eyes, chemosis, granulomas, ptosis, and scleral show. Plast Reconstr Surg J 2010;125:709-18. 